\title{
Worsening Drought of Nile Basin under shift in Atmospheric Circulation, Stronger ENSO and Indian Ocean Dipole
}

\author{
Shereif Mahmoud \\ University of Alberta \\ Thian Yew Gan ( $\sim$ tgan@ualberta.ca ) \\ University of Alberta \\ Richard Allan \\ University of Reading \\ Jianfeng Li \\ Hong Kong Baptist University \\ Chris Funk \\ University of California, Santa Barbara
}

\section{Research Article}

Keywords: Climate change, hydroclimate, droughts, streamflow, Nile River basin

Posted Date: September 29th, 2021

DOI: https://doi.org/10.21203/rs.3.rs-913507/v1

License: (c) (1) This work is licensed under a Creative Commons Attribution 4.0 International License. Read Full License 


\section{Worsening Drought of Nile Basin under shift in Atmospheric Circulation, Stronger ENSO and Indian Ocean Dipole}

Shereif H. Mahmoud ${ }^{1}$, Thian Yew Gan ${ }^{1 *}$, Richard Allen ${ }^{2}$, Jianfeng $\mathrm{Li}^{3}$, and Funk, C. ${ }^{4}$

${ }^{1}$ Department of Civil and Environmental Engineering, University of Alberta, Edmonton, T6G 1H9, Canada

${ }^{2}$ Department of Meteorology, University of Reading, Berkshire, RG6 6BB, United Kingdom

${ }^{3}$ Department of Geography, Hong Kong Baptist University, Hong Kong

${ }^{4}$ Climate Hazards Center, University of California Santa Barbara, CA 93106, United States of America

*Corresponding Author: tgan@ualberta.ca

Until now, driving mechanisms behind recurring droughts and hydroclimate variations that controls the Nile River Basin (NRB) remains not well understood. In this study, we demonstrate that the recent increasing aridity of NRB is attributed to the growing influence of stronger ENSO and Indian Ocean dipole (IOD), and SST gradient over the Arabian Sea (WTIO) in NRB after 1980s, which have significantly contributed to NRB's drought severity at interannual to inter-decadal timescales. Further, the southward (westward) shift in stream functions and meridional (zonal) winds caused an enhancement in the blocking pattern, with strong anticyclonic waves of dry air that keeps moving into NRB, has resulted in drier NRB, where its streamflow at gauging stations have decreased from 137 to 114.1 $\mathrm{m}^{3} / \mathrm{s} /$ decade. Contrary to past findings, we demonstrate that IOD and WTIO are better predictors of the Nile streamflow than El Niño. Under the combined impact of warming and stronger WTIO and El Niño, future droughts of the NRB will worsen.

Keywords: Climate change, hydroclimate, droughts, streamflow, Nile River basin 


\section{Introduction}

Since the beginning of ancient civilizations in Africa, the Nile River has been the major source of water supply to its eleven riparian countries. However, since the 1970 s, recurring droughts ${ }^{1-4}$, changes to the timing and amount of precipitation, and increasing population have led to rising tension between competing users for water and growing political instability ${ }^{5}$. The Fifth Assessment Report (AR5) of the Intergovernmental Panel on Climate Change (IPCC) concluded that drying had occurred over much of Africa and the number of hydrologic extremes and heat stress have doubled since the middle of the $20_{\text {th }}$ century ${ }^{5,6}$. Past studies predominantly confined to a specific sub-basin and have not provided us with a clear perspective on the driving mechanisms behind recurring droughts and the hydroclimate variations that controls the Nile River Basin (NRB). Among various causes of droughts identified in Africa ${ }^{1-4}$ are the decline in precipitation related to warming caused by rising concentration of greenhouse gases ${ }^{4,7}$. Past studies also show that precipitation in the Blue Nile Basin (BNB) ${ }^{8-11}$ with high spatial and temporal variability is affected by El Niño Southern Oscillation (ENSO) such that positive anomalies (wet years) tend to occur during the negative phase of ENSO ${ }^{12-14}$, while negative anomalies (dry years) during the positive phase of ENSO, and the timing of ENSO events.

Conversely, BNB's precipitation and flow tend to be high during La Niña years but low during El Niño years ${ }^{15,16}$, and extreme droughts correspond to strong El Niño events. The frequency of severe droughts occurring in NRB at interannual to inter-decadal time scales is linked to variations in Atlantic temperatures ${ }^{3}$, while long-term variations of NRB precipitation is linked to the African monsoon ${ }^{17}$. An important question to address is: are NRB droughts primarily caused by precipitation anomalies attributed to ENSO, or have other factors also contributed to its drought severity,

such as the warming trend of Africa ${ }^{18}$, increasing frequency of extreme El Niño events under climate warming ${ }^{16,19}$, and changes in atmospheric circulation ${ }^{20}$ associated with anthropogenic greenhouse gas or aerosol forcing, volcanic effects or internal unforced variability ${ }^{21}$. In view of disparaging results reported on hydroclimatic changes of the NRB, there is an urgent need to better understand changes in the hydrological cycle of NRB. The flow of NRB comes from two sources, the Blue Nile and the White Nile, which join at Khartoum, the capital city of Sudan (Fig. 1). The BNB occupies about $11 \%$ of the NRB but it contributes about $60 \%$ of the Nile River flow ${ }^{22}$. With a total catchment area of 3.1 million $\mathrm{km}^{2}$, the NRB is shared by eleven countries, namely, Burundi, Rwanda, Uganda, Kenya, Tanzania, South Sudan, Democratic Republic of Congo, Sudan, Eritrea, Ethiopia, and Egypt. About $86 \%$ of NRB's area lies in Sudan, 
Ethiopia, and Egypt. Despite its recurrent occurrences, we have yet to explain droughts of NRB satisfactorily because most past drought studies mainly focus on precipitation anomalies, soil moisture, and vegetation indices of the BNB ${ }^{8-}$ 10,12. Here, we analyzed the hydroclimate data of NRB to identify key driving forces behind climate warming and droughts in NRB, and the variability of the Nile flow data over 1900-2012 in three gaging stations, and implications of flow variability to the severity and intensity of hydrological droughts in each riparian country of the NRB. We also identify mechanisms that control sensitivities of droughts, and the teleconnection of droughts and hydroclimate of NRB to ENSO and the dipole modes of the Indian Ocean. This study is first to investigate the full range of possible climate change impacts on NRB's hydroclimate, droughts, and correct some disparaging results reported in past studies. The results from this study would help us to develop more effective mitigation strategies for these riparian countries against the potential impact of future droughts.

\section{Results}

Abrupt changes in the NRB's hydroclimate under climate warming. To conduct a broad-scale analysis of the hydroclimatic changes of NRB, Pettitt's test and Mann-Kendall (MK) were applied to monthly precipitation, surface temperature, geopotential height, relative humidity, specific humidity, potential and actual evapotranspiration, wind speed, zonal and meridional wind stresses, Nile flow, surface runoff, soil moisture content (SMC), and total water storage (TWS) data of the NRB (see methods sections). The NRB has experienced significant climate change impact in recent decades, as shown in a statistically significant change point (1976) in surface temperature (Ts) (HadCRUT4), with a statistically significant warming trend of $0.19{ }^{\circ} \mathrm{C} /$ decade over 1976-2017 (Fig.1a, supplementary Table 1). A statistically significant change point was also detected (1970) in the monthly precipitation anomaly data from five different datasets (Udel., GPCC, 20CRv3, CRU.TS4.03, and GPCC V2018) with an overall decreasing trend of 16.2 $\mathrm{mm} /$ decade (Fig.1b) and increasing trend in wind speed and zonal wind stress (NCEP-NCAR) at $0.02 \mathrm{~m} / \mathrm{decade}$ and $1.51 \mathrm{~m}^{2} / \mathrm{s}^{2} /$ decade respectively since 1975 (Fig.1c). For the 1948-2017 relative humidity data (RH) (20CRv3), a statistically significant change point was detected in 1977, with a significant decreasing trend of $0.35 \% /$ decade after 1977 (Fig.1d). Similarly, a statistically significant change point (1976) was detected in monthly 1000-mb geopotential height (GPH) data (20CRv3), and an increasing trend of $3.1 \mathrm{~m} /$ decade (Fig.1f). As expected, higher Ts had resulted in higher $\mathrm{GPH}^{23}$, which means the lower atmosphere had become warmer. A statistically significant change point (1994) was also detected in the monthly specific humidity data of 1948-2017, and a slight increasing trend of 0.15 
$\mathrm{g} / \mathrm{kg}$ per decade, with the mean specific humidity increasing from $8.6 \mathrm{~g} / \mathrm{g}$ in 1948-1994 to $8.8 \mathrm{~g} / \mathrm{g}$ in 1994-2017 (Fig.1e).

In addition, from the 1950-2017 reference and actual evapotranspiration (AET) estimated for NRB using a surface energy balance algorithm (see methods section), the AET of NRB has increased significantly with an upward trend of $14.4 \mathrm{~mm} /$ decade (supplementary Fig. 1b, and supplementary Table 2) since 1990s. Furthermore, a statistically significant change point was detected in monthly SMC and TWS in 1979, and after the change point, SMC and TWS data exhibit significant negative trends of $0.84 \mathrm{~mm} /$ decade and $1.44 \mathrm{~mm} /$ decade, respectively (supplementary Figs 15c and Fig. 16c). Analysis of Niño3.4 data (ERSST) shows a statistically significant change point in 1978, with the mean Niño3.4 (ERSST) increasing from $-0.2{ }^{\circ} \mathrm{C}$ over $1910-1978$ to $0.52{ }^{\circ} \mathrm{C}$ over $1978-2017$ (Fig.1g), a statistically significant increasing trend of $0.17^{\circ} \mathrm{C} /$ decade. Since 1970s, changes between the El Niño index and the "relative" El Niño (the El Niño index with the global warming signal deducted) shows that El Niño have become stronger with higher intensity by climate warming in recent years (Fig. 1g). To further confirm the location of the abrupt variations in the NRB's hydroclimate, seven commonly used nonparametric single and multiple change detection methods were applied to the NRB's hydroclimate data (see methods section). Supplementary Table 2 shows the exact location of these variations using each detection method. The results obtained from these methods confirm the location of the hydroclimate variations in the NRB. For instance, posterior probability-based methods sch as BCP, PELT, and Pettitt clearly confirm the statistically significant change points in NRB's precipitation, RH, wind speed, specific humidity, GPH, AET, SMC, and TWS in 1970, 1977, 1975, 1994, 1976, 1995, and 1979, respectively.

Attribution of changes in NRB's hydroclimate. From the SD (standard deviation) of the Niño3.4 index and relative El Niño3.4 (El Niño3.4r) estimated over 20-, 30-, 40- and 50-year windows in Fig. 2a,b, it is clear that the degree of ENSO variability has increased in NRB over the 1980-2017 period marked by several extreme El Niño events occurring over this period. The difference between El Niño amplitudes with and without the global warming signal in Figs. 2a, b clearly shows that El Niño events have grown to be stronger in recent years by climate warming. In Fig. 2d, the Indian Ocean dipole (IOD), also known as the Indian "Niño", defined by a zonal SST gradient, also exhibited increasing variability similar to ENSO, where the SD of IOD over 1970-2017 was characterized by strong and frequent occurrences of positive events associated with El Niño events. Fig. 2c also shows a statistically significant change point in 1993 , where the mean IOD of $0.02{ }^{\circ} \mathrm{C}$ over $1950-1993$ increased to $0.25^{\circ} \mathrm{C}$ over $1993-2017$, which means an 
overall statistically significant increasing trend of about $0.1{ }^{\circ} \mathrm{C} /$ decade, for IOD had been in a positive phase since 1993. Figs 2e and $2 \mathrm{f}$ also show that higher zonal wind stresses are associated with stronger El Niño, their amplitude in terms of wind speed and discharging effect also increased with stronger El Niño events and climate warming.

A wavelet coherence analysis (WTC) shows that the hydroclimate of NRB is strongly correlated with El Niño and IOD (supplementary Figs. 8 and 9). The strong WTC (anti-phase) between El Niño and IOD, and precipitation and RH after 1970s shows that El Niño and IOD had contributed to lower precipitation (drying) over NRB, and their significant in-phase relationship with Ts and GPH shows that stronger El Niño (El Niño3.4r) and IOD after 1970s was related to climate warming ${ }^{16}$. In addition, WTC plots between AET and El Niño show in-phase, statistically significant coherent relationship at 2-4 and 8-14-years bands after 1970s (supplementary Fig 6a, b), which peaked at 14-16-year time scale after 2000s. On the other hand, the wavelet coherence between IOD and AET show that IOD primarily lead AET after 2000s. Based on WTC and a detailed detrended cross correlation ( $\rho$ ) analysis (DCCA), the hydroclimate of NRB is strongly teleconnected to El Niño and IOD (Fig. 3) at inter-annual to inter-decadal timescales, with positive or negative correlations between El Niño 3.4, $\mathrm{T}_{\mathrm{s}}(\rho=0.97$ ) (Fig. 3a), GPH ( $\rho=0.81)$ (Fig. 3b), RH ( $\rho=-0.97$ ) (Fig. 3c) and precipitation ( $\rho=-0.7)$ (Fig. 3d).

The strong correlation between these climate variables and IOD show that IOD plays an important role on the hydroclimate variability of NRB. For instance, the strong negative correlation between IOD, precipitation $(\rho=-0.37)$ (p-value $<0.05)$ and the Standardized Precipitation Index (SPI) $(\rho=-0.87)$ demonstrate that besides El Niño, IOD has also contributed to lower precipitation and more severe droughts of NRB (Fig. 3d and 6a-f), similar to the teleconnection between East African precipitation, ENSO and IOD ${ }^{27}$. The higher AET after 1970s can be partly attributed to stronger wind stresses associated with stronger El Niño amplitudes, as shown by strong WTC between zonal and meridional wind stresses and AET at 1-2-year bands (Fig.3e-f, supplementary Figs. 6 and 7). DCCA also showed a significant positive correlation between AET and El Niño 3.4 ( $\rho=0.93)$, and meridional wind stresses ( $\rho$ =0.62). Apparently, increasing meridional wind stress anomalies and stronger El Niño and IOD events have both contributed to the increased aridity in NRB (Fig. 3f, supplementary Fig.7). It is shown that whenever drought occurs, the air temperature tends to be higher than the mean temperature because more net solar energy is received (less clouds) while less energy is used to evaporate water or soil moisture ${ }^{28}$. 
The influence of ENSO and IOD on drought conditions of NRB. Some studies have teleconnected droughts of the upper part of the $\mathrm{NRB}^{9,10}$ and sub-Saharan Africa ${ }^{21}$ to ENSO based on a single drought index such as SPI or Normalized vegetation index (NDVI). However, in our study, the frequency, intensity, change point and trend of the meteorological, agricultural, and hydrological droughts of NRB under the effect of climate change were investigated based on the SPI index, the Normalized vegetation index (NDVI), the Standardized Precipitation-Evapotranspiration Index (SPEI), the self-calibrating Palmer Hydrological Drought Index (sc-PDSI), and runoff anomaly, estimated over 1950-2017, respectively (see methods section). Beside ENSO, our results show that IOD plays a more crucial role on NRB's hydroclimate variability and drought severity over inter-decadal and longer timescales (Fig.4 and supplementary Fig. 9). The SPI index was computed at 1, 3, 6, 12 and 48-month timescales for NRB over 1950-2017. The 1-month SPI time series (supplementary Fig. 3a) shows statistically significant change point in 1979 with a decreasing trend of 0.15/decade (supplementary Table 3). By defining droughts as SPI <-1, recurrent droughts were detected in 1952, 1959, 1965, 1972, 1973, 1978, 1983, 1984, 1987, 1991, 1994, 1999, 2002, and 2011, respectively, with increasing severity after late 1970s. The 48-month SPI (Fig.4a) also exhibits overall decreasing trends since 1970s, but of higher magnitude than the 1-month SPI.

To consider the effect of warming and potential evapotranspiration (PET) on drought severity, the SPEI index at 1, 3, 6, 12 and 48-month timescale for 1940-2018 was computed over the NRB from five precipitation datasets (Udel., GPCC, 20CRv3, CRU.TS4.03, and GPCC V2018). Like the SPI index, the 48-month SPEI index from the five datasets consistently shows a statistically significant change point in 1983 with a decreasing trend of 0.1 to $0.15 /$ decade (Fig. 4c). The consistent results obtained from the above five datasets confirm that higher PET intensified by warming had a significant impact on NRB during the most dominant drought events between 1970 and 2018. The sc-PDSI time series for NRB also shows a significant change point in 1983, with an overall decreasing trend of $0.58 /$ decade, as reflected by hydrologic droughts in 1973 and 1987, and then recurrent droughts between 2002 and 2011 (Fig.4e). This means that more frequent hydrologic droughts have occurred over NRB than the global average since early $2000 \mathrm{~s}^{32}$.

In NRB, rain-fed agriculture is the prevailing agricultural system, and thus negative runoff anomalies are good indicators for hydrologic droughts as well as lower agricultural productivity. The monthly observed runoff anomalies in NRB between 1902 and 2014 in Fig. 4g show a statistically significant change point in 1970 with a decreasing trend of $1.2 \mathrm{~mm} /$ decade. Fig 4(g) also shows the response (drying) of agricultural and vegetation cover (right-hand side of 
Fig. 4g) to the decline in runoff between 1981 and 2014. The negative monthly runoff anomaly after 1970s indicate a lower runoff availability to rain-fed agriculture and ecosystems and increases the severity of droughts in NRB. Before 1970s, the WTC plots show that El Niño and IOD were in phase with both sc-PDSI, SPI, and SPEI, but after 1970s their relationships became predominantly anti-phase. These posts 1970s results suggest that stronger El Niño and IOD events contributed to more severe droughts in NRB after 1970s (Fig.4c-e and supplementary Fig. 9e-f), as is also evident from the strong negative correlation between El Niño (IOD) and SPI (Fig. 4b), $\rho=-0.86$ (-0.87), SPEI (Fig. 4d), $\rho=-0.89$ (-0.25), sc-PDSI (Fig. 4f), $\rho=-0.75$ (-0.41), and runoff anomaly (Fig. 4h), $\rho=-0.84$ (-0.39). Results obtained from using NDVI shows that an increase in AET and a decline in precipitation could lead to severe agricultural droughts (supplementary Fig.4) in irrigated areas of the Ethiopian highlands, Ethiopia, Eritrea, Kenya, Tanzania, Congo and Uganda since the 1970s.

The role of western and southeastern Indian Ocean on NRB's hydroclimate and drought. To further investigate the role of IOD on the hydroclimate of NRB, DCCA and WTC analysis using the two halves of IOD, i.e., the western pole (WTIO) over the Arabian Sea $\left(50^{\circ} \mathrm{E}-70^{\circ} \mathrm{E}, 10^{\circ} \mathrm{S}-10^{\circ} \mathrm{N}\right)$ and the southeast Indian Ocean (SEIO) $\left(90^{\circ} \mathrm{E}\right.$ to $110^{\circ} \mathrm{E}$, $10^{\circ} \mathrm{S}$ to $0^{\circ} \mathrm{N}$ ) shows that SST of the WTIO plays a primary role on NRB's hydroclimate over inter-decadal and longer timescales. The dominant anti-phase relationship between WTIO and NRB's precipitation, SPI and scPDSI at interdecadal timescales (> 32-year) show that NRB's hydroclimate is more strongly linked to the SST gradient over WTIO than to IOD and El Niño (supplementary Fig.10a-f), which is also evident in the significant negative correlation between WTIO and the precipitation variability of NRB $(\rho=-0.82)$. Apparently, more frequent occurrences of droughts in NRB are related to increased warming in the WTIO (supplementary Fig.11a) and other factors, as is also evident from the strong negative correlation between SPI and SST of WTIO ( $\rho=-0.71$ for SPI and -0.8 for sc-PDSI) (supplementary Fig.11b-c). There are strong anti-phase relationships at 16-32 (32-64) year bands between WTIO (SEIO) and SMC (TWS) (supplementary Fig. 17a-d), with significant negative correlations between NRB's SMC and SEIO ( $\rho=-0.92$ ), and WTIO ( $\rho=-0.83$ ) (supplementary Fig. 17e), e.g., NRB's SMC decreased under stronger SEIO and WTIO amplitudes. The strong negative correlation between TWS and SEIO $(\rho=-0.95)$ and WTIO $(\rho=-0.91)$ implies that increased Indian Ocean SST gradient over WTIO and SEIO resulted in lower TWS in NRB (supplementary Fig.17f). Apparently, WTIO and SEIO explain the variability of NRB's SMC and TWS more than IOD (see supplementary Fig.17-18). 
Responses of Nile flow variability to ENSO and IOD. To better understand hydrologic droughts of NRB, we also investigated the Nile flow variability and the teleconnection of ENSO and the dipole mode to Nile flow over 19122012. Observed annual flow records for 1912-2012 from the Blue Nile station at Khartoum (Fig.5a) show a statistically significant change point in 1964, with a decreasing trend of about $13.7 \mathrm{~m}^{3} / \mathrm{s} /$ decade after 1964 . Between 1965 and 1987, the Blue Nile flow decreased so much that the mean annual flow after 1965 was below the long-term mean annual flow by $716 \mathrm{~m}^{3} / \mathrm{s}$ (supplementary Fig.12a, supplementary Table 4). The annual flow of the Dongola station also showed a significant decline during 1900-1982 (Fig.5b), while the annual flow of the Aswan station in 1900-1987 exhibited high temporal variability, e.g., the August-November wet season over 1900-1950 shows high flow records (supplementary Fig.12(b-c)), a statistically significant change point in 1965, and a statistically significant negative trend of $114.1 \mathrm{~m}^{3} / \mathrm{s}$ after 1965 (Fig. 5c and supplementary Fig.13b). The 30-, 50- and 100-yr moving average of NRB' annual runoff further indicate lower runoff after 1970s (Fig. 6a).

Figure. 6b-c shows a significant negative correlation between the Nile flow and IOD (s.d.) ( $\rho=-0.71$ for the Blue Nile, and -0.57 for the Nile at Dongala station), compared to a less significant negative/positive correlation between El Niño (s.d.) and the Nile flow at the Blue Nile $(\rho=-0.31)$ and Dongala stations $(\rho=0.25)$, respectively. Therefore, IOD exerts a stronger influence on the Nile flow than El Niño at inter-annual to inter-decadal time scales. The peak correlation between IOD and the Nile flow occurred a year earlier than that between El Niño and the Blue Nile flow, which agrees with WTC between IOD and El Niño (i.e., one lead the other as shown in supplementary Fig. 5a, b). The increasing intensity in El Niño (s.d.) after 1978 (represented by the change point (yellow color) in Fig.6b) shows that El Niño occurred more frequently with positive IODs than La Niña events with negative IODs. Our results show a strong negative correlation between the Nile flow (Blue Nile flow) and the Indian Ocean SST gradient over WTIO and SEIO (Fig. 6d-e), e.g., between the Nile flow (Blue Nile flow) and WTIO, $\rho=-0.72(-0.92)$; and SEIO, $\rho=-0.58(-0.88)$. This demonstrates that the Nile flow is strongly linked to SST gradient of WTIO and SEIO, with their warm (cold) phase is associated with decreased (increased) Nile flow (see arrows in Fig. 6d), or to SST of WTIO and SEIO, and El Niño at inter-annual to multi-decadal time scales.

Atmospheric circulation patterns. To better understand changes to the atmospheric circulation over NRB, we analyzed the responses of stream function fields, GPH, and zonal / meridional winds to climate warming and ENSO (Fig. 7a-h). Associated with El Niño (La Niña) events, the 750-mb stream function show positive (negative) stream 
function anomalies, which correspond to high (low) GPH anomalies. The anomalous, anticyclonic stream function pattern is associated with ENSO warming, that propagates from the northwest towards southern and eastern parts of NRB during El Niño events (Fig.7a), controlling the circulation of air mass, heat, and moisture in the NRB. During La Niña events (Fig.7b), north-eastern anticyclone wave originates over the Arabian Peninsula and travelling west over the Red Sea and part of the Indian ocean towards Egypt, Libya and part of Sudan, with negative stream function anomalies only over the BNB, Tanzania, and Uganda. Changes in stream function patterns are attributed to more El Niño and fewer La Niña events occurring after 1970s. Fig.7c-h shows the composite 300-mb GPH and zonal and meridional wind anomaly patterns associated with El Niño and La Niña events, respectively.

Similarly, the composite map of GPH anomalies at 300-mb during El Niño events is characterized by spatially persistent, positive anomalies, and shows an intensive anticyclonic flow, which is advective dry air, from the north (Arabian Peninsula) westward towards the NRB. In particular, the Ethiopian highlands, the Sudd region in South Sudan, Eritrea, Uganda, and the Aswan high dam of Egypt showed the highest positive GPH anomalies during El Niño events (Fig.7c). In contrast, GPH anomalies during La Niña events show mainly negative anomalies except in the Arabian Peninsula, (Fig.7d). Fig. 7c, d implying that El Niño induced positive GPH anomalies are more consistent spatially than the negative anomalies during La Niña events. This can be attributed to the thermal inertia associated with El Niño events, i.e., El Niño induced positive GPH anomalies are more persistent and are intensified by warming. This finding indicates a warmer lower troposphere, resulting in higher Ts and drier weather (lower dew points) in NRB.

Differences in U-wind (meridional winds) patterns between Figs. 7e and 7f (Figs, 7g and 7h) show an enhanced, positive zonal U-wind and meridional winds flow anomaly during El Niño events. Fig. 7a-d also shows the shift in zonal winds (westward) and meridional winds (southward) associated with stronger El Niño events, which have contributed to the increased aridity of NRB after 1970s and resulted in a reorganization of the atmospheric circulation over NRB. Changes in regional atmospheric circulations based on stream function, GPH and U-wind anomalies associated with El Niño events further demonstrates that more persistent and stronger El Niño has resulted in drier NRB. For instance, the zonal U- wind patterns in Fig. 7e, flow from the northwest toward NRB as anomalous anticyclone waves, moving drier air continuously into the NRB and tend to be very strong over the Ethiopia's lowland, Uganda, Burundi, the Sudd region in South Sudan, the Roseries, Eritrea, and Congo. Beside the observed change in 
zonal wind pattern, meridional wind anomalies associated with El Niño events shifted south (Fig. 7g). This observed changes in wind patterns associated with stronger El Niño events (Figs, 7e and 7g) have contributed to the abrupt changes in the NRB's hydroclimate as shown by DCCA, WTC, and the spatial correlation between El Niño and NRB's hydroclimate.

Response of NRB's hydroclimate and drought to future projection of ENSO and IOD. Our analysis indicates that IOD and WTIO are likely better predictors of the streamflow of the Nile than El Niño. Therefore, we have projected WTIO and IOD from simulations of 34 global climate models (GCMs) of CMIP5 ${ }^{36}$ over 1900-2100 (see Fig. 8 and supplementary Figs. 25-26). The correlation between the multi-model ensemble (MME) of WTIO and IOD obtained from GCMs' projections and WTIO and IOD estimated from ERSST data range between $\rho=0.61$ and $\rho=0.88$ (supplementary Fig.26a). The results show that the variability (s.d.) of WTIO has increased since the 1970s in both the observed dataset and the MME of 34 GCMs' simulations for the historical run, which means that WTIO has become warmer in recent decades, and it is projected to be considerably warmer at a trend of 0.01 to 0.023 ${ }^{0} \mathrm{C} /$ decade between 2019 and 2100 (Fig. 8, supplementary Fig.26b-d). The warmer WTIO, the more intensive El Niño, and atmospheric circulation shift in recent years are expected to play a major role modulating the future climatic conditions of NRB, likely resulting in less precipitation, RH, SMC, and the Nile flow, as warming continues in NRB over the $21^{\text {st }}$ Century. Under the projected increase in WTIO over the Arabian sea, future drought conditions of NRB is expected to worsen. Supplementary $26 \mathrm{a}-\mathrm{d}$ shows projected increasing trends of 0.01 to $0.02{ }^{\circ} \mathrm{C} / \mathrm{dec}$ de in IOD over 2019-2100, which could double the increasing trend in IOD observed between 1993 and 2018. As future positive IOD events are projected by GCMs to be more extreme because of global warming, NRB could suffer from more severe droughts which could occur more frequently in the future.

To estimate the influence of the projected increase in WTIO, IOD and El Niño on the NRB's hydroclimate and droughts, future projections of NRB's hydroclimate and droughts were also analyzed (supplementary Figs. 22-24). Based on the analysis of simulations of 34 GCMs of CMIP5, the warming of NRB is projected to be at $0.24{ }^{\circ} \mathrm{C} / \mathrm{dec}$ ade $\left(0.36{ }^{\circ} \mathrm{C} /\right.$ decade) (supplementary Figs.22 and 23a), annual precipitation is projected to decrease at about 16.5 $\mathrm{mm} /$ decade, $\mathrm{RH}$ is projected to decline at $0.87 \%$ /decade (1.04 \% /decade), PET is projected to increase at 11.4 $\mathrm{mm} /$ decade $(18.4 \mathrm{~mm} /$ decade $)$, and monthly SMC is projected to decrease at $0.12 \mathrm{~mm} / \mathrm{dec}$ ade $(0.72 \mathrm{~mm} / \mathrm{decade})$, under Representative Concentration Pathways RCP 2.6 (RCP4.5) scenarios over 2020-2050, respectively. With high 
spatial variability in precipitation, the annual precipitation in Egypt and Sudan could decline by $15.5 \mathrm{~mm} / \mathrm{decade}$ but for the White Nile region, it could increase by $28.9 \mathrm{~mm} / \mathrm{decade}$ over 2020-2050 (supplementary Fig.23b). Between 2050 and 2100 , the warming trend will continue but projected at a lower rate, annual precipitation is projected to increase at $5 \mathrm{~mm} /$ decade, $\mathrm{RH}$ is projected to only decline at $0.23 \% /$ decade $(0.34 \% /$ decade $)$, monthly SMC is projected to decrease at $0.65 \mathrm{~mm} /$ decade $(2.5 \mathrm{~mm} / \mathrm{decade})$, and PET to increase by $10 \mathrm{~mm} / \mathrm{decade}$ ( $14.8 \mathrm{~mm} / \mathrm{decade})$ under RCP 2.6 (RCP4.5), respectively. It seems that agricultural drought of NRB will get worse over the $21^{\text {st }}$ Century. Climate models project more frequent and stronger El Niño events between 2020 and $2100^{16,37}$, leading to worsening droughts and more severe surface drying in NRB over the $21^{\text {st }}$ century. Furthermore, large parts of Egypt and Sudan are projected to suffer mild to moderate hydrologic droughts over the $21^{\text {st }}$ Century (supplementary Fig.24), and countries such as Kenya, Tanzania, Rwanda, Burundi, Uganda, and Congo are projected to suffer incipient droughts.

\section{Discussion}

The results of this study have brought new insight on the hydroclimate variability of NRB, provide a clearer perspective on the driving mechanisms behind the hydroclimate variations and worsening droughts of NRB in recent decades, and have corrected some disparaging results reported in past studies. Low precipitation and climate warming have been attributed as key driving forces to droughts of Africa $^{1-5}$. Our results show significant hydroclimatic changes that contributed to recent increasing aridity of NRB since the 1970s. This is evident in the decreasing trend in precipitation, RH, SMC, and TWS, and increasing trend in wind speed, wind stresses, GPH, Ts, and AET. The increase in AET is also shown by other studies, that higher AET is related to higher wind speed and wind stresses, warming and lower $\mathrm{RH}^{24-26}$. These observed changes are strongly linked to El Niño and IOD. Our results demonstrate that warming, El Niño and IOD have played a crucial role on NRB's inter-decadal hydroclimate variability, but IOD has played a more important role in modulating NRB's hydroclimate at higher timescales than El Niño.

A composite analysis of NRB's hydroclimate data between 1948 and 2017 also shows significant changes across the entire NRB (supplementary Figs. 20 and 21). For instance, $T_{\mathrm{s}}$ has increased at 0.16-0.4 C\%/decade over the NRB, with the highest increase in Ethiopia, Uganda, Sudan, and Egypt (supplementary Fig.21a). Because of climate warming, RH has decreased by 1-5\%/decade after 1985, with the largest decrease in Ethiopia, Uganda, and Sudan where warming has also been the worst (supplementary Fig.21b). The SMC shows high spatial variabilities in NRB but at a decreasing trend of 16-45 mm/decade between 1985 and 2017 (supplementary Fig.21c). At a positive trend of 0.2- 
$0.8 \mathrm{~m}^{2} / \mathrm{sec}^{2}$ between 1985 and 2017, the increase in scalar wind was maximum in Uganda, Sudan, and northwestern regions of Ethiopia, where both meridional and Zonal wind have also increased (supplementary Fig.20c-e). These changes had resulted in lower daily precipitation (supplementary Fig.20a), marginally higher specific humidity (supplementary Fig.20b), lower annual surface runoff (supplementary Fig.21c), but higher PET (supplementary Fig.21e). As expected, higher AET is found in irrigated land and water bodies in the Ethiopian highlands and in countries of southern NRB such as Uganda, Egypt, Sudan, Burundi, Congo, Kenya, Rwanda, and Tanzania, where water losses from high AET can be substantial (supplementary Fig. 2). These results also show that higher wind speed and wind stresses tend to blow away humid air from land, resulting in a drier atmosphere.

The lower atmosphere stream function of supplementary Fig.21f at 0.8458 sigma level, which depicts the rotational part of the flow (the flow is along the contours), indicates that main waves emanating from northern towards southern parts of NRB, have shifted further south from 1948-1984 to 1985-2017. This long-term southward shift in the stream function over NRB would have also contributed towards the long-term drying of NRB, as part of multiple changes attributed to climate warming, e.g., changes in precipitation, Ts, wind stresses, GPH, RH, SMC, TWS, surface runoff, and AET. Our analysis also shows that the influence of stronger ENSO and IOD in NRB has increased after 1970s, particularly the influence of IOD on NRB's hydroclimate over inter-decadal timescales. The IOD's power spectrum and significant coherence with ENSO, demonstrate a strong coupling between them, for both exhibited similar change patterns, e.g., positive IOD becomes more intensive as the strength of El Niño increases (supplementary Fig. 5). As a result, the impact of El Niño and IOD events in the hydroclimate of NRB have increased because of climate warming, which have contributed to the observed long-term trends in NRB's hydroclimate since the 1970s. The enhanced zonal and meridional wind stresses attributed to stronger atmospheric heating after 1980s could have also contributed to more severe aridity in NRB, such as statistically significant increasing trends in the warm spell duration (WSD) and maximum daily temperature over NRB at about 3.1 day/decade and $0.35{ }^{\circ} \mathrm{C} /$ decade since 1975 , respectively (supplementary Fig. 1a and supplementary Table 1).

To better understand how El Niño and IOD influence each riparian country of NRB, we estimated spatial correlation between IOD and El Niño and NRB's hydroclimate. Our findings show that the influence of El Niño over NRB's hydroclimate varies widely across the entire basin spatially as shown by the spatial correlation between El Niño and NRB's GPH, Ts, precipitation, RH, and AET for the past 70 years. El Niño events have had a stronger warming effect 
in the upper part of the NRB, as shown by the strong positive correlation $(\rho=0.3-0.9)$ between Ts and El Niño in Ethiopia, Kenya, Uganda, Rwanda, Burundi, Tanzania, Eretria, and Sudan (Fig. 9a), leading to higher WSD over NRB at about 3.1 day/decade since 1975 (supplementary Fig 1a), which is expected given recent stronger El Niño events have been linked to greenhouse warming ${ }^{15,16}$. These results are within agreement with ENSO-induced warming over Kenya $\left(0.15^{\circ} \mathrm{C} /\right.$ decade $)$ and Ethiopia $\left(0.3^{\circ} \mathrm{C} /\right.$ decade $)$ since $1970 s^{29,30}$. In addition to El Niño-induced warming in NRB, the spatial correlation between NRB's precipitation and El Niño shows a strong negative (positive) correlation between El Niño and precipitation in lowland of Ethiopia, Sudan, Uganda, Rwanda, and Burundi (Kenya, Tanzania, and Egypt) (Fig. 9b). This finding agrees with that of de la Poterie et al. ${ }^{61}$, who reported above (below) average precipitation in Kenya (Ethiopia) during El Niño years.

Furthermore, RH (AET) is negatively (positively) correlated with El Niño in the Ethiopian's lowlands, Sudan, South Sudan, Uganda, Kenya, Eritrea, Burundi, and Rwanda (Fig. 9c, d), which shows that a decrease (increase) in NRB's RH (AET) attributed to El Niño warming effect in the NRB since the 1970s. Byrne and O'gorman ${ }^{31}$ have also found a similar relationship between land RH and increased warming in recent years. The results of the DCCA, WTC and trend analysis between El Niño and the NRB's hydroclimate over the past 70 years provide evidence of El Niño induced changes on the NRB's hydrological cycle. Our results also indicate that El Niño induced impacts on the NRB's hydroclimate can either be intensified or decreased, depending on the strength of IOD events. For instance, the spatial correlation between NRB's surface temperature and IOD in Fig. 10a shows a mirror image of El Niño warming signal over the NRB's riparian countries. We also demonstrate that IOD amplifies the impact of ENSO on NRB's precipitation variability, as shown by the significant negative correlation between IOD and precipitation in Eritrea, Ethiopia, Sudan, Congo, and Egypt (Fig. 10b). Beside El Niño, IOD has also contributed to lower precipitation in these countries, an opposite pattern to the teleconnection between East African precipitation, ENSO and IOD ${ }^{27}$, which shows positive correlation with ENSO and IOD. Fig. 10b also shows a significant positive correlation between IOD and precipitation in Uganda, Kenya, Tanzania, Burundi, and Rwanda. The negative influence of IOD on Ethiopian's precipitation was also shown by Korecha and Barnston ${ }^{62}$. In contrast to El Niño induced impacts on the NRB's RH and AET over the past 70 years, our findings show that IOD have a positive effect on NRB's RH (increase) i.e., lower AET (Fig. 10c, d). This is evident in the statistically significant positive (negative) correlation between IOD and RH over Egypt and northern parts of Sudan (Ethiopian highlands, Kenya, and Tanzania). In other words, the relationship between NRB's RH and AET and IOD shows an opposite pattern to their relationship with El Niño. Fig. 10c, 
$d$ also show that IOD reduced El Niño negative influence on RH over Egypt and northern parts of Sudan and intensified the influence over Ethiopian highlands, Kenya, and Tanzania resulting in higher AET over these countries.

The role of the changes in NRB's hydroclimate, hydrological cycle and warming-induced drought stress is evident in the consistent results obtained from drought indices representing meteorological, agricultural, and hydrological droughts in NRB, which show repetitive drought episodes, with increasing severity after 1970s. These indices support the archived historical information on drought events in NRB. For instance, the 48-month SPI exhibits overall decreasing trends since 1970s, the SPEI index computed over the NRB from five precipitation datasets confirm that higher AET intensified by warming had a significant impact on NRB during the most severe drought events that occurred 1970 and 2018, and the sc-PDSI index also reflected recurrent hydrologic droughts in the NRB after 1970s. These findings show that more frequent hydrologic droughts have occurred over NRB than the global average since early $2000 \mathrm{~s}^{32}$, resulting in severe agricultural droughts in Ethiopia, Eritrea, Kenya, Tanzania, Congo, and Uganda since the 1970s (supplementary Fig.4). Our results also show that El Niño and IOD events contributed to more severe droughts in NRB after 1970s, and that IOD have a greater influence in NRB's drought over inter-decadal to longer timescales as shown by WTC and the strong negative correlation between ENSO and IOD, and sc-PDSI, SPI, SPEI and runoff anomalies.

Furthermore, from WTC and strong negative correlations between SPI, sc-PDSI and WTIO, NRB's hydroclimate is shown to be more strongly influenced by WTIO than by IOD, and the Nile flow is more strongly teleconnected to IOD and WTIO than El Niño at inter-annual and inter-decadal time scales. Contrary to past findings ${ }^{11,20,22}$, our results show that IOD and WTIO are better predictors of the Nile flow than El Niño. To further investigate drought conditions of NRB, composite analysis of the NRB's hydroclimate data, sc-PDSI, Ts, and precipitation of each riparian country of NRB are analyzed individually (supplementary Table 5). Even though the degree of climate warming in NRB varies from one riparian country to another (supplementary Table 5), overall impacts to meteorological, agricultural, and hydrological droughts of most riparian countries of NRB have been severe, where regional warming trends have exceeded the mean global warming trend of about $0.15^{\circ} \mathrm{C}$ per decade ${ }^{33}$. Lastly, given the inter-annual variability of the Nile flow is also projected to increase significantly from the $20^{\text {th }}$ to the $21^{\text {st }}$ century ${ }^{34}$, it could lead to even more severe droughts in NRB in future. 
Beside the observed warming, El Niño -driven changes to wind patterns have also contributed to a drier NRB in recent years. A westward shift in zonal winds and southward shift in meridional winds, caused an enhancement in the blocking pattern, with strong anticyclonic waves of dry air that keeps moving dry air over the Roseires, lowlands of Ethiopia, the Sudd region in South Sudan, Eritrea, Congo, Uganda, and Burundi. This pattern controls the circulation of air mass, heat, and moisture fluxes in NRB, which explain the observed changes in NRB's hydroclimate. In other words, changes in atmospheric circulations over NRB due to the southward shift of the lower atmospheric stream functions, GPH, El Niño-wind patterns has resulted in the observed changes in NRB's hydroclimate and intensified drought. This is also evident in the WTC and DCCA between AET and wind stresses, which shows that wind stresses have had a positive (negative) influence on NRB's AET (RH), i.e. The increase in wind stresses lead to increase (decrease) in AET and Ts (RH). Andresen et al. ${ }^{35}$ showed a similar effect of El Niño -driven changes to wind patterns in the United States, lower precipitation, and significant warming. Lastly, warming over the Arabian sea and stronger El Niño and IOD attributed to warming, have together contributed to worsening droughts observed in NRB in recent years, where its flow at upstream and downstream stations have decreased from 13.7 to $114.1 \mathrm{CBM} /$ decade, respectively. Climate projections suggest that under the combined impact of warming and stronger WTIO and El Niño episodes, future droughts of the NRB will worsen.

\section{Methods:}

Observational datasets. Historical monthly temperature, relative humidity, and specific humidity data for 1900-2017 were taken from the 20th Century Reanalysis V2 Dataset, the 20th Century Reanalysis V2 data provided by NOAA/OAR/ESRL (https://www.esrl.noaa.gov/psd/). Temperature anomaly data for 1910-2017 was taken from the HadCRUT4 global temperature dataset developed by the Climatic Research Unit of University of East Anglia (CRU.Ts4.03) $)^{38}$ in conjunction with the Hadley Centre (UK Met Office). Historical observed monthly precipitation data for 1948-2017 was taken from the University of Delaware precipitation dataset (Udel. ${ }^{39}$ ) developed from a large number of climate stations of the Global Historical Climate Network, We have also analyzed precipitation data from the following datasets (i) the $20^{\text {th }}$ Century Reanalysis V3 Dataset provided by the NOAA/OAR/ESRL PSL, Boulder, Colorado, USA (20CRv3), (ii) the University of East Anglia's Climate Research Unit (CRU.TS4.03) https://crudata.uea.ac.uk/cru/data/hrg/cru_ts_4.04/, (iii) the $0.25^{\circ}$ Gridded data of Global Precipitation Climatology Center (GPCC v2.2), (iv) GPCC Full Data Monthly Product Version 2018 extended with GPCC Monitoring Monthly Product version 6 (GPCC v.6) (https://opendata.dwd.de/climate_environment/GPCC/html/download_gate.html), (v) JRA-55 reanalysis dataset, and (vi) NCEP/NCAR Reanalysis dataset. Monthly Geopotential height, zonal and meridional wind stresses, and wind speed from 1948-2017 were drawn from the National Centers for Environmental

Prediction- National Center for Atmospheric Research (NCEP- NCAR) reanalysis 1 (NCEP-R1) and the 40-yr 
European Center for Medium-Range Weather Forecasts (ECMWF) Re-Analysis (ERA-40). Digital elevation model (DEM) of $30 \mathrm{~m}$ resolution was obtained from the Global Elevation Model (GDEM) version 2 databases (http:// aster.usgs.gov). The Nile River hydroclimate from these datasets were calculated as the average of all grid boxes within the basin boundary from each dataset.

Monthly precipitation and temperature data in gridded form $\left(0.5^{\circ} \times 0.5^{\circ}\right)$ from $1948-2017$ was obtained from the Global monthly precipitation and temperature data of the Princeton global forcings ${ }^{40}$. These datasets are of the observational-reanalysis hybrid type developed from a combination of datasets, which include the NCEP-NCAR reanalysis dataset ${ }^{41}$, the TRMM dataset, the CRU TS2.0, the GPCP, and the NASA Langley Research Center SRB products ${ }^{40}$. These are credible datasets are widely used in climatology studies due to their robustness for variability analyses $^{42-44}$. Total atmospheric water vapor content was extracted from the MODIS atmosphere profiles product (MOD07), and emissivity data were derived from averaging MODIS-bands 31 and 32, while the land cover map taken from the global land cover of Africa archive of 2008 and was updated using available Landsat images (http://www.africover.org./index.htm). Land cover map was derived from the global land cover of Africa archive of the year 2008 and was updated using available Landsat images. (http://www.africover.org./index.htm), long term observed monthly Nile River flow data were collected from three stations, the monthly flows at Dongola stationSudan, Aswan dam station (1900-1984), and the Blue Nile station in Khartoum from 1900 to 1984 were extracted from the Global River Discharge Database (RivDIS v1.1), in addition we obtained the monthly flows at the Blue Nile station from recorded measurements between 1984-2012.

Area-averaged of TWS were computed from water balance model based on GLADS-CLSM025 TWS between 19482017 and the Gravity Recovery and Climate Experiment (GRACE) between 2003 and 2017. NRB's soil moisture data were was computed as an area average of ERA-Interim, CLM v.4, FLDAS, WaterGAP model, and GLDAS soil moisture datasets. Long-term runoff observation for the Nile River basin was extracted from the GRUN- Runoff observation-based global gridded runoff dataset ${ }^{45}$ from 1902 to 2014 . This dataset was newly developed for climatological, hydrological, and environmental studies and are close to near natural runoff conditions and represent the excess of water available to ecosystems. Warm spell duration (WSD), the annual number of days contributing to events where 6 or more consecutive days experience a daily maximum temperature TX > 90th percentile was extracted from the HadEX2 observational data set. CMIP5 RCP2.6, RCP4.5, and RCP8.5 experiments over the period 19002100 from 34 global climate models (GCMs) of CMIP5. The models included ACCESS1-0, ACCESS1-3, CCSM4, CNRM-CM5, CSIRO-MK3-6-0, FGOALS-g2, GFDL-CM3, GFDL-ESM2G, GFDL-ESM2M, GISS-E2-R, HadGEM2-CC, HadGEM2-ES, IPSL-CM5A-LR, IPSL-CM5A-MR, IPSL-CM5B-LR, MIROC5, MIROC-ESM, MPI-ESM-LR, MPI-ESM-MR, MRI-CGCM3, NorESM1-M and NorESM1-ME.

Statistical analysis, trends, and change point of NRB's hydroclimate. We first did a detailed analysis of monthly precipitation, surface temperature, geopotential height, relative humidity, specific humidity, potential and actual evapotranspiration, wind speed, zonal and meridional wind stresses data of the NRB, Nile flow, surface runoff, SMC, and TWS data. These data were first checked to ensure quality control and homogenization, downscaled to the NRB, 
then the non-parametric statistic of Pettitt's test ${ }^{46}$ and the modified-Mann-Kendall ${ }^{47}$ codes were written in R-software and employed to detect abrupt changes and trends in these variables. Pettitt's test is defined as:

$K_{T}=\max \left|U_{t}, T\right|$

Where,

$U_{t}, T=\sum_{i=1}^{n-1} \sum_{j=t+1}^{n} \operatorname{sgn}\left(x_{j}-x_{i}\right)$

$K_{T}$ is the detected change-point of the series if it is statistically significant. The p-value of $K_{T}$ is approximated by:

$p \approx 2 e^{-6 K_{T}^{2} / T^{3}+T^{2}}$

The non-parametric Mann-Kendall test statistic is calculated according to:

$S=\sum_{i=1}^{n-1} \sum_{j=i+1}^{n} \operatorname{sgn}\left(x_{j}-x_{i}\right)$

Trend is estimated for a time series $x_{i}, \mathrm{i}=1,2 \ldots \mathrm{n}-1$ and $x_{j}, \mathrm{j}=\mathrm{i}+1, \mathrm{i}+2 \ldots \mathrm{n}$. Each $x_{i}$ is a reference and compared with remaining data points $x_{j}$ (see 5):

$\operatorname{Sgn}\left(x_{j}-x_{i}\right)= \begin{cases}+1 & \text { if }\left(x_{j}-x_{i}\right)>0 \\ 0 & \text { if }\left(x_{j}-x_{i}\right)=0 \\ -1 & \text { if }\left(x_{j}-x_{i}\right)<0\end{cases}$

The variance statistic is estimated as:

$\operatorname{Var}(S)=\frac{n(n-1)(2 n+5)-\sum_{j=1}^{p} t_{j}\left(t_{j}-1\right)\left(2 t_{j}+5\right)}{18}$

Where $\mathrm{p}$ is the number of groups in which each group consists of data points of equal values, and $t_{j}$ is the number of data points in the jth tied group. The statistic $\mathrm{S}$ is approximately normal distributed by the following $\mathrm{Z}$-transformation:

$Z= \begin{cases}\frac{S-1}{(\operatorname{Var}(S))^{0.5}} & \text { if } S>0 \\ 0 & \text { if } S=0 \\ \frac{S+1}{(\operatorname{Var}(S))^{0.5}} & \text { if } S<0\end{cases}$

The slope $(\mathrm{Tj})$ is computed according to $\mathrm{Sen}^{48}$ as follow:

$T_{j}=\frac{x_{j}-x_{i}}{j-1}$

To ensure accurate detection of change point in the NRB's hydroclimate, we have written R-codes for seven other change points detection methods (Bayesian change point detection (BCP), non-parametric multiple change-point analysis (MCP), lepage sequential and batch change detection method (CPM), optimal multiple change point algorithms (PELT), structure change features method (SCFM), bayesian information criterion (BIC), and segmentation by Dynamic Programming (DP)) and applied them to the NRB's hydroclimate. Unlike Pettitt's test, BCP method given in Wang and Emerson ${ }^{49}$ provides a tool for evaluating the strength of abrupt changes "posterior probability" at each point of the time series, where points with the highest posterior probability are considered true change points. In another word, the detection rate of BCP depends more on the magnitude of change than other methods. Similarly, BIC method provides a strongly consistent selection of the optimal number of change points in a timeseries $^{50}$. BIC is derived from an asymptotic expression of the Bayes factor, therefore, has been applied straightforwardly in change-point models. In the MCP method given in Matteson and James ${ }^{51}$, the estimation of the most likely locations of change point within the timeseries is based on a hierarchical clustering using the energy 
statistics. CPM is an approach to sequential change detection, which allows standard statistical hypothesis tests to be deployed sequentially to detect single and multiple change points ${ }^{52}$. PELT given in Killick et al. ${ }^{53}$ estimates multiple change points using penalization. The main drawback of this method is that it requires a user specified penalty term. In addition to the above methods, we have also applied the SCFM method to detect the change point in the NRB's hydroclimate. The main difference between above methods and SCFM is that SCFM provides confidence intervals of change points like Pettitt's test. Lastly, the DP method described in Muggeo ${ }^{54}$ was used to further confirm the locations of the estimated change points.

Surface energy balance algorithm. The FAO-56 Penman-Monteith method ${ }^{55}$ was used to model reference evapotranspiration on a grid-by-grid basis. Then, surface energy balance data were used to estimate actual evapotranspiration of NRB for 1912-2018, and from which their variability and anomalies were analyzed. To estimate AET, first the net solar radiation (Rn), NDVI, albedo, roughness length, and soil heat flux (G) were calculated in ArcGIS 10.1. ESRI's ArcGIS. Then the surface energy balance algorithm was employed to model AET based on the approach given in Bastiaanssen et $\mathrm{al}^{56}$.

Drought detection methods. The frequency, intensity, change point and trend of the meteorological, agricultural, and hydrological droughts of NRB under the effect of climate change were investigated based on the SPI, NDVI, SPEI, sc-PDSI, and runoff anomaly index, estimated, respectively. SPI computation was made based on the method proposed by McKee et al. ${ }^{57}$ and Edwards and McKee ${ }^{58}$. This computation was made to drive SPI at different scale at 1, 3, 6, 12 and 48-month. The SPEI at 1, 3, 6, 12 and 48-month timescales over 1940-2018 was computed for the NRB from five precipitation datasets (Udel., GPCC, 20CRv3, CRU.TS4.03, and GPCC V2018) as the monthly difference between precipitation (Pr) and PET. For example, for the month i, $S P E I_{i}=P r_{i}-P E T_{i}$, where $P r_{i}$ is the monthly precipitation obtained from GPCC, 20CRv3, CRU.TS4.03, JR-55, NCEP/NCAR-R1, and GPCC V2018 and $P E T_{i}$ is the monthly PET based on FAO-56 Penman-Monteith method ${ }^{55}$. This index have a crucial advantage over other drought indices that consider the effect of PET on drought severity due to its ability to identify different drought types and the impacts of global warming. NDVI data for the year 2002 to 2017 was extracted from the U.S. Geological Survey (USGS) Earth Resources Observation and Science (EROS) Center "eMODIS" products. The theory behind the popularity of NDVI in agricultural drought studies comes from its dependency on the near infrared reflectance (NIR) from vegetation cover and the visible-red reflectance $(\mathrm{RED})$. Where NDVI $=(\mathrm{NIR}-\mathrm{RED}) /(\mathrm{NIR}+\mathrm{RED})$, these two reflectance components measure the density of chlorophyll contained in vegetative cover. NDVI change detection model was developed in ArcGIS model builder to capture the change in NDVI through time and identify areas with agricultural droughts. The sc-PDSI was obtained from Climate Analysis Section of the National Center for Atmospheric Research in a gridded format and was used as a reference for actual sc-PDSI calculation. The computation of the sc-PDSI was made using the sc-PDSI package in R-software and is based on the approach adapted in Wells et al. ${ }^{59}$. Runoff anomaly index was calculated from the long-term runoff observation for the Nile River basin between 1902 to 2014.

Wavelet Analysis and wavelet coherence. We have written R-code for the Morlet wavelet analysis and used it to investigate the temporal variability, periodicities, and the cyclic behavior of NRB's hydroclimate. To evaluate the possible impacts of El Niño and IOD on the hydroclimate of the NRB, wavelet coherence was also used to estimate 
the spatio-temporal correlation field between these hydroclimate variables and El Niño and IOD. The wavelet power spectra of each time series were calculated as follow:

$W_{x, \Psi}(s, t)=\left(X(t) * \Psi_{s}(t)\right)$

Where $t$ is the time series, $\Psi_{s}$ is the Morlet mother wavelet at the scale $s$. The Morlet mother wavelet can be defined as follow:

$\Psi_{S}(\eta)=\pi^{-1 / 4} e^{\iota \omega_{s} \eta} e^{-\eta^{2} / 2}$

where, $\eta$ is time, $\omega_{s}$ is frequency, and $\iota$ (imaginary number) which is the square root of minus one.

We have also analyzed the phase difference between NRB's hydroclimate (drought indices and flow), El Niño and IOD using the methodology of Torrence and $\mathrm{Compo}^{60}$. The phase difference provides information about the possible delay in the relationship between NRB's hydroclimate (drought indices and flow) and El Niño and IOD. The WTC coefficient is given as:

$R^{2}(s, t)=\frac{\left|S\left(s^{-1} W_{x y}(s, t)\right)\right|^{2}}{S\left(s^{-1}\left|W_{x}(s, t)\right|^{2}\right) * S\left(s^{-1}\left|W_{y}(s, t)\right|^{2}\right)}$

Where $\mathrm{x}$ is the hydroclimate variable (drought indices or flow) been analyzed and $\mathrm{y}$ is El Niño or IOD. $\mathrm{t}$ is the dimensionless time-shift parameter, $W_{x y}(s, t)$ is the cross wavelet transform of the two-time series, $W_{x}$ and $W_{y}$ are the sums of ranks of observations in $x$ and $y$, respectively, and $\mathrm{S}$ is a smoothing operator, which was calculated based on the approach of Torrence and $\mathrm{Compo}^{60}$.

Composite analysis and spatial correlation. To investigate the hydroclimate variability and the spatio-temporal changes in the NRB's hydroclimate, composite maps of precipitation, Ts, GPH, RH, specific humidity, scalar wind, meridional and zonal wind, soil moisture, surface runoff, and PET data were derived by the difference between data of 1985-2017 and data of 1948-1984. Composite analysis of the NRB's hydroclimate data between 1948 and 2017 and sc-PDSI, monthly temperature, temperature anomaly, monthly precipitation and precipitation anomaly were also analyzed for each riparian country of NRB, to relate climate warming to trend and change points in hydrologic droughts of these countries. We have further estimated the spatial correlation between NRB's hydroclimate and El Niño and IOD to better explain in greater details the teleconnection of ENSO and IOD to each riparian country of NRB.

Detrended Cross Correlation Analysis. For non-stationary data, detrended cross correlation analysis (DCCA) ensures that the results obtained are not affected by trend. Therefore, DCCA was used to investigate the role of ENSO and IOD on the NRB's hydroclimate, flow variability, and droughts over inter-decadal and longer timescales. For instance, DCCA between IOD and El Niño amplitudes and NRB's precipitation, Ts, GPH, RH, specific humidity, PET, AET, wind speed, zonal and meridional wind stresses, drought indices, Nile flow, surface runoff, SMC, and TWS were used to estimate the teleconnection of ENSO and IOD on NRB's hydroclimate data divided over 30-year 
running periods from 1920 to 2017. The DCCA coefficients of hydroclimate variable $x(i)$ and El Niño or IOD $y(i)$ were calculated as follow:

$X_{k}=\sum_{i=1}^{k} x_{i}$ and $Y_{k}=\sum_{i=1}^{k} y_{i}$, where $k=1, \ldots, N$.

First, the hydroclimate variables, El Niño, and IOD were divided into equal length segments $\left(N_{n}\right)$. Then, using regression models, we have defined the local trend in each segment $\breve{X}_{n, s}(k)$ and $\breve{Y}_{n, s}(k)$, where $s=1, \ldots, N_{n}$. The time series data $X_{k}$ and $Y_{k}$ are detrended by subtracting the local trends $\breve{X}_{n, s}(k)$ and $\breve{Y}_{n, s}(k)$ from original time-series in each segment. Next, we calculated the detrended covariance and variance function in each segment as follow:

$F_{D C C A}^{2}(n)=\frac{1}{n N_{n}} \sum_{\mathbf{d}=1}^{N_{n}} \sum_{k=n(s-1)+1}^{n s}\left[X(k)-\dot{X}_{n, s}(k]\left[Y(k)-\dot{Y}_{n, s}(k]\right.\right.$

Then, the detrended variance of the two-time series, $f_{D F}$, is calculated as follow:

$f_{D F A, X(n)}=\sqrt{\frac{1}{N-n} \sum_{i=1}^{N-n}\left[1 /(n-1) \sum_{k}^{i+n}\left(X_{k}-\tilde{X}_{k, i}\right)\right]}$

$f_{D F A, Y(n)}=\sqrt{\frac{1}{N-n} \sum_{i=1}^{N-n}\left[1 /(n-1) \sum_{k}^{i+n}\left(Y_{k}-\tilde{Y}_{k, i}\right)\right]}$

This calculation is repeated for all segment, if the series are power-law cross-correlated, then $V_{D C C A} \sim n^{2 \tau}$. The $\tau$ exponent is the long-range power-law cross correlation between two-time series, and is calculated through linear regression of $\log \left[V_{D C C A}(n)\right]$ and $\log \mathrm{n}$. Finally, the DCCA cross correlation coefficient $(\rho)$ was calculated according to:

$\rho=\frac{F_{D C C A(n)}^{2}}{f_{D F A, X(n)} f_{D F A, Y(n)}}$

The value of $\rho$ ranges from -1 to 1 , a value of $\rho=0$ means there is no cross-correlation between the two-time series being analyzed.

Detection and attribution methods. The observed ENSO and Indian Ocean dipole (IOD) amplitude, and zonal and meridional winds stresses over the NRB were derived and analyzed. ENSO and IOD amplitude were estimated as the standard deviation (SD) of the Niño3.4 and IOD index over 20-, 30-, 40- and 50-year windows from 1950 to 2017 using the ERSST data sets. Zonal and meridional wind stresses amplitude $\left(10^{-1} \mathrm{~N} \mathrm{~m}^{-2}\right)$ were calculated as the SD of zonal and meridional winds stresses over 20-, 30-, 40- and 50-year windows from 1950 to 2017, using NCEP/NCAR data sets of 1950-2017. Then, composite analysis, DCCA and WTC were used to investigate the role of ENSO and IOD on the NRB's hydroclimate variability and drought severity over inter-decadal and longer timescales. Furthermore, to investigate changes in regional atmospheric circulation we analyzed the responses of stream function fields, GPH, and zonal / meridional winds to climate warming and ENSO. For the March-April-May (MAM), JuneJuly-August (JJA), September-October-November (SON) and December-January-February (DJF) seasons of 19502017, stream function fields, GPH, and zonal / meridional winds composites were computed as the ratio of mean seasonal stream function fields, GPH, and zonal / meridional winds in anomalous (El Niño) years relative to the long 
term mean seasonal stream function fields, GPH, and zonal / meridional winds. To emphasize the effect of El Niño on seasonal stream function fields, GPH, and zonal / meridional winds, years with strong El Niño activity (1958, 1982, 1983, 1987, 1992 and 1997, 2005) were only considered in the composite analysis.

To better understand hydrologic droughts of NRB, we also investigated the Nile river flow variability and the teleconnection of ENSO and the dipole mode to Nile flow over 1912-2012. The NRB flow are computed over 30-year running periods from 1913 to 2010 for the Blue Nile station, and from 1913 to 1984 for Dongala station. El Niño 3.4, IOD, SEIO, WTIO amplitudes are computed as the SD of the El Niño 3.4, IOD, SEIO, WTIO indexes over 30-year windows from 1913 to 2017, using the ERSST data sets. We have also analyzed the projected WTIO and IOD using climate projections of 34 global climate models (GCMs) of CMIP5. Future projection of WTIO and IOD were analyzed based on climate projections of 34 global climate models (GCMs) of CMIP5. First, WTIO was estimated as areally weighted SST simulated by each GCM over the Arabian sea $\left(50^{\circ} \mathrm{E}\right.$ to $70^{\circ} \mathrm{E}$ and $10^{\circ} \mathrm{S}$ to $\left.10^{\circ} \mathrm{N}\right)$. Then, the multimodel ensemble (MME) of the WTIO computed from the simulations of 34 GCMs was computed over 30-year periods from 1913 to 2100 . WTIO estimated from the GCM that best agrees with the observed WTIO was selected. Furthermore, projections of IOD between 2019 and 2100 were computed as the difference between Western $\left(50^{\circ} \mathrm{E}\right.$ to $70^{\circ} \mathrm{E}$ and $10^{\circ} \mathrm{S}$ to $\left.10^{\circ} \mathrm{N}\right)$ and Eastern $\left(90^{\circ} \mathrm{E}\right.$ to $110^{\circ} \mathrm{E}$ and $10^{\circ} \mathrm{S}$ to $\left.0^{\circ} \mathrm{N}\right) \mathrm{SST}$ of the Indian ocean simulated by the 34 GCMS. Lastly, based on RCP scenarios of 34 GCMs of CMIP5 ${ }^{6}$, future changes to the annual precipitation, temperature, PET, SMC, relative humidity, sc-PDSI, El Niño 3.4 index, and IOD of NRB until 2100, and their impact to hydrological droughts of NRB were projected.

\section{Data availability.}

The observational data, flow data and remote sensing data that support the findings of this study are available from the corresponding author upon reasonable request.

Codes availability. R-codes for abrupt changes, wavelet analysis, and attributions can be obtained from the first author upon request.

\section{Acknowledgments}

The first author was funded by a recruitment scholarship of the University of Alberta, and by the Natural Science and Engineering Research Council of Canada between 2016 and 2020. The authors would like to thank Compute Canada's WestGrid support staff for their assistance with technical issues of its supercomputers.

\section{Author contributions}

Gan T.Y. conceived the study, Mahmoud S.H. collected the observational datasets, calculated the change points and trends of the NRB's hydroclimate, conducted the wavelet and drought analysis, the attribution methods, the detrended correlation analysis, the analysis of CMIP and NRB's flow data, and atmospheric circulation analysis with the help of Gan, T. Y. Gan T.Y. and Mahmoud S.H. led the writing of the paper, while all authors contributed to the interpretation, discussions of results and the writing of the manuscript. 
Competing Interests. The authors declare that there is no competing interest.

\section{References}

1. Giannini, A., Saravanan, R., Chang, P. Oceanic forcing of Sahel rainfall on interannual to interdecadal time scales. Science 302, 1027-1030 (2003).

2. Zeng, N. Drought in the Sahel. Science 302, 999-1000 (200J3).

3. Shanahan, T.M., Overpeck, J.T., Anchukaitis, K.J., Beck, J.W., Cole, J.E., Dettman, D.L., Peck, J.A., Scholz, C.A., King, J.W. Atlantic forcing of persistent drought in West Africa. Science 324, 377-380 (2009).

4. Williams, A., Funk, C. A westward extension of the warm pool leads to a westward extension of the Walker circulation drying eastern Africa. Climate Dynamics, 1-19 (2011).

5. Mahmoud, S.H. Hydroclimate Changes to Arid regions subjected to Impact of climate change, human activities, and Large-scale climate patterns', $\mathrm{PhD}$, University of Alberta, Edmonton (2020).

6. IPCC. Climate Change 2014: Synthesis Report. Contribution of Working Groups I, II and III to the Fifth Assessment Report of the Intergovernmental Panel on Climate Change [Core Writing Team, R.K. Pachauri and L.A. Meyer (eds.)]. IPCC, Geneva, Switzerland, 151 pp (2014).

7. Ramanathan, V., Crutzen, P.J., Kiehl, J.T., Rosenfeld, D. Aerosols, climate, and the hydrological cycle. Science 294, 2119-2124 (2001).

8. Seleshi Y., Camberlin, P. Recent changes in dry spell and extreme rainfall events in Ethiopia. Theoret Appl Climatol 83:181-191 (2006).

9. Nyeko-Ogiramoi, P., Willems, P., Ngirane-Katashaya, G. Trend and variability in observed hydro-meteorological extremes in the Lake Victoria basin. J. Hydrol. 489, 56-73 (2013).

10. Tabari, H., Taye, M. T., \& Willems, P. Statistical assessment of precipitation trends in the upper Blue Nile River basin. Stochastic environmental research and risk assessment, 29(7), 1751-1761 (2015).

11. Onyutha, C., Tabari, H., Taye, M. T., Nyandwaro, G. N., \& Willems, P. Analyses of rainfall trends in the Nile River Basin. Journal of hydro-environment research, 13, 36-51 (2016).

12. Gissila, T., Black, E., Grimes, D.I.F. and Slingo, J.M. Seasonal forecasting of the Ethiopian summer rains. Int J Climatol 24:1345-1358 (2004).

13. Segele ZT, Lamb PJ, Leslie, L.M. Seasonal-to-inter annual variability of Ethiopia/Horn of Africa monsoon. Part I: associations of wavelet-filtered large-scale atmospheric circulation and global sea surface temperature. J Clim 22:3396-3421 (2009).

14. Abtew, W., Melesse, A. M., \& Dessalegne, T. El Niño southern oscillation link to the Blue Nile River basin hydrology. Hydrological Processes, 23(26), 3653-3660 (2009).

15.Cai, W., Wang, G., Santoso, A., McPhaden, M.J., Wu, L., Jin, F.F., Timmermann, A., Collins, M., Vecchi, G., Lengaigne, M. and England, M.H. Increased frequency of extreme La Niña events under greenhouse warming. Nat. Clim. Change 5, 132-137 (2015).

16. Kim, S.T., Cai, W., Jin, F.F., Santoso, A., Wu, L., Guilyardi, E. and An, S. I. Response of El Niño sea surface temperature variability to greenhouse warming. Nat. Clim. Change 4, 786_790 (2014). 
17.Zhao, Y., Colin, C., Liu, Z., Paterne, M., Siani, G., \& Xie, X. Reconstructing precipitation changes in northeastern Africa during the Quaternary by clay mineralogical and geochemical investigations of Nile deep-sea fan sediments. Quaternary Science Reviews, 57, 58-70 (2012).

18. Serdeczny, O., Adams, S., Baarsch, F., Coumou, D., Robinson, A., Hare, W., Schaeffer, M., Perrette, M., Reinhardt, J. Climate change impacts in Sub-Saharan Africa: from physical changes to their social repercussions. Reg. Environ. Change 17(6), 1585-1600 (2016).

19.Cai, W., Borlace, S., Lengaigne, M., Van Rensch, P., Collins, M., Vecchi, G., Timmermann, A., Santoso, A., McPhaden, M.J., Wu, L. and England, M.H. Increasing frequency of extreme El Niño events due to greenhouse warming. Nat. Clim. Change 4(2), 111 (2014).

20. Siam, M. S., Demory, M. E., \& Eltahir, E. A. Hydrological cycles over the Congo and Upper Blue Nile Basins: Evaluation of general circulation model simulations and reanalysis products. Journal of Climate, 26(22), 8881-8894 (2013).

21. Nath, R., Luo, Y., Chen, W., \& Cui, X. On the contribution of internal variability and external forcing factors to the Cooling trend over the Humid Subtropical Indo-Gangetic Plain in India. Scientific reports, 8(1), 1-11. (2018)

22. Conway, D. From headwater tributaries to international river: observing and adapting to climate variability and change in the Nile Basin. Global Environ. Change 15, 99-114 (2005).

23. Gong, D. Y., Drange, H., \& Gao, Y. Q. Reconstruction of Northern Hemisphere 500 hPa geopotential heights back to the late 19th century. Theoretical and Applied Climatology, 90(1-2), 83-102 (2007).

24. Fischer, E. M. \& Knutti, R. Robust projections of combined humidity and temperature extremes. Nat. Clim. Change 3, 126-130 (2013).

25.Zaroug, M., Eltahir, E. A. B., and Giorgi, F. Droughts and floods over the upper catchment of the Blue Nile and their connections to the timing of El Niño and La Niña events, Hydrology and Earth System Sciences 18(3), DOI: 10.5194/hess-18-1239 (2014).

26. Eslamian, S., Khordadi, M. J., \& Abedi-Koupai, J. Effects of variations in climatic parameters on evapotranspiration in the arid and semi-arid regions. Global and Planetary Change, 78(3), 188-194 (2011).

27. Tierney, J. E., Smerdon, J. E., Anchukaitis, K. J., \& Seager, R. Multidecadal variability in East African hydroclimate controlled by the Indian Ocean. Nature, 493(7432), 389. (2013).

28. Huang, J., Yu, H., Dai, A., Wei, Y., \& Kang, L. Drylands face potential threat under 2 C global warming target. Nature Climate Change, 7(6), 417-422. (2017).

29. Ongoma, V., Chen, H., Gao, C. and Sagero, P.O. Variability of temperature properties over Kenya based on observed and reanalyzed datasets. Theoretical and Applied Climatology, 133(3-4), pp.1175-1190. (2018).

30.Jury, M. R., \& Funk, C. Climatic trends over Ethiopia: regional signals and drivers. International Journal of Climatology, 33(8), 1924-1935. (2013).

31. Byrne, M. P., \& O'gorman, P. A. Understanding decreases in land relative humidity with global warming: Conceptual model and GCM simulations. Journal of Climate, 29(24), 9045-9061. (2016).

32. Sheffield, J., Wood, E. F., \& Roderick, M. L. Little change in global drought over the past 60 years. Nature, 491(7424), 435. (2012). 
33. Gizaw, M., and Gan, T. Y., Impact of Climate Change and El Niño Episodes on Droughts in sub-Saharan Africa, Climate Dynamics, Springer, https://doi.org/10.1007/s00382-016-3366-2 (2016).

34. Siam, M. S., \& Eltahir, E. A. Climate change enhances interannual variability of the Nile river flow. Nat. Clim. Change, 7, 350-354 (2017).

35. Andresen, J., Hilberg, S., Kunkel, K., \& Center, M. R. C. (2012). Historical climate and climate trends in the Midwestern USA. US National Climate Assessment Midwest Technical Input Report, 1-18. (2012).

36. IPCC. Climate Change 2014: Synthesis Report. Contribution of Working Groups I, II and III to the Fifth Assessment Report of the Intergovernmental Panel on Climate Change [Core Writing Team, R.K. Pachauri and L.A. Meyer (eds.)]. IPCC, Geneva, Switzerland, 151 pp (2014).

37. University of East Anglia Climatic Research Unit; Harris, I.C.; Jones, P.D: CRU TS4.03: Climatic Research Unit (CRU) Time-Series (TS) version 4.03 of high-resolution gridded data of month-by-month variation in climate (Jan. 1901- Dec. 2018). Centre for Environmental Data Analysis (2020).

38. Matsuura, K.; Willmott, C. Terrestrial Precipitation: 1900-2017 Gridded Monthly Time Series (1900-2017) (v 5.01). University of Delaware. 2018. http://climate.geog.udel.edu/ climate/html_pages/download.html (accessed on 15 April 2018).

39. Sheffield J, Goteti G, Wood EF. Development of a 50-year high-resolution global dataset of meteorological forcings for land surface modeling. J. Clim. 19(13): 3088-3111. (2006).

40. Kalnay E, Kanamitsu M, Kistler R, Collins W, Deaven D, Gandin L, Iredell M, Saha S, White G, Woollen J, Zhu Y, Leetmaa A,Reynolds R, Chelliah M, Ebisuzaki W, Higgins W, Janowiak J, Mo KC, Ropelewski C, Wang J, Jenne R, Joseph D. The NCEP/NCAR 40-year reanalysis project. Bull. Am. Meteorol. Soc.77(3): 437-471. (1996).

41. Hoell A, Shukla S, Barlow M, Cannon F, Kelley C, Funk C. The forcing of monthly precipitation variability over Southwest Asia during the Boreal Cold Season. J. Clim. 28(18): 7038-7056. (2015).

42.Zeng R, Cai X. Climatic and terrestrial storage control on evapotranspiration temporal variability: Analysis of river basins around the world. Geophys. Res. Lett. 43(1): 185-195. (2016).

43. Onyutha, C., \& Willems, P. Influence of spatial and temporal scales on statistical analyses of rainfall variability in the River Nile basin. Dynamics of Atmospheres and Oceans, 77, 26-42. (2017).

44. Ghiggi, G., Humphrey, V., Seneviratne, S. I., \& Gudmundsson, L. GRUN: an observation-based global gridded runoff dataset from 1902 to 2014. Earth System Science Data, 11(4), 1655-1674. (2019).

45. Pettitt, A. N. A non-parametric approach to the change-point problem. Applied statistics, 126-135. (1979).

46. Yue, S., and Wang, C. The Mann-Kendall test modified by effective sample size to detect trend in serially correlated hydrological series. Water Resources Management,18(3),201-218. (2004).

47. Sen, P.K., Estimates of the regression coefficient based on Kendall's tau. J. Am. Stat. Assoc. 63, 1379-1389. (1968).

48. Wang, X., \& Emerson, J. W. Bayesian change point analysis of linear models on graphs. arXiv preprint arXiv:1509.00817. (2015).

49. Schwarz, G. Estimating the dimension of a model. The annals of statistics, 6(2), 461-464. (1978).

50. Matteson, D. S., \& James, N. A. A nonparametric approach for multiple change point analysis of multivariate data. Journal of the American Statistical Association, 109(505), 334-345. (2014). 
51. Ross, G. J. Parametric and nonparametric sequential change detection in R: The cpm package. Journal of Statistical Software, 66(3), 1-20. (2015).

52. Killick, R., Fearnhead, P., \& Eckley, I. A. Optimal detection of changepoints with a linear computational cost. Journal of the American Statistical Association, 107(500), 1590-1598. (2012).

53. Muggeo, V.M.R. Estimating regression models with unknown breakpoints. Statistics in Medicine22, 3055-3071. (2003).

54. Allen, R. G., Pereira, L. S., Raes, D., \& Smith, M. Crop Evapotranspiration-Guidelines for computing crop water requirements-FAO Irrigation and drainage paper 56. Fao, Rome, 300(9), D05109. (1998).

55. Bastiaanssen, W. G., Menenti, M., Feddes, R. A., \& Holtslag, A. A. M. A remote sensing surface energy balance algorithm for land (SEBAL). 1. Formulation. Journal of hydrology, 212, 198-212. (1998).

56. McKee TB, Doesken NJ, Kleist J. The relationship of drought frequency and duration to time scales. In Proceedings of the 8th Conference on Applied Climatology. AMS: Boston, MA; 179-184. (1993).

57.Edwards, D. C., and T. B. McKee. Characteristics of 20th century drought in the United States at multiple time scales. Colorado State University Dept. of Atmospheric Science Climatology Rep. 97-2/Atmospheric Science Paper 634, 174 pp. (1997)

58. Wells, Nathan, Steve Goddard, and Michael J. Hayes. "A self-calibrating Palmer drought severity index." Journal of Climate 17.12: 2335-2351 (2004).

59. Torrence, C., \& Compo, G. P. A practical guide to wavelet analysis. Bulletin of the American Meteorological society, 79(1), 61-78. (1998).

60. de la Poterie, A. S. T., Jjemba, W. E., Singh, R., de Perez, E. C., Costella, C. V., \& Arrighi, J. Understanding the use of 2015-2016 El Niño forecasts in shaping early humanitarian action in Eastern and Southern Africa. International Journal of Disaster Risk Reduction, 30, 81-94. (2018).

61. Korecha, D., \& Barnston, A. G. Predictability of June-September rainfall in Ethiopia. Monthly weather review, 135(2), 628-650. (2007). 


\section{Figures}
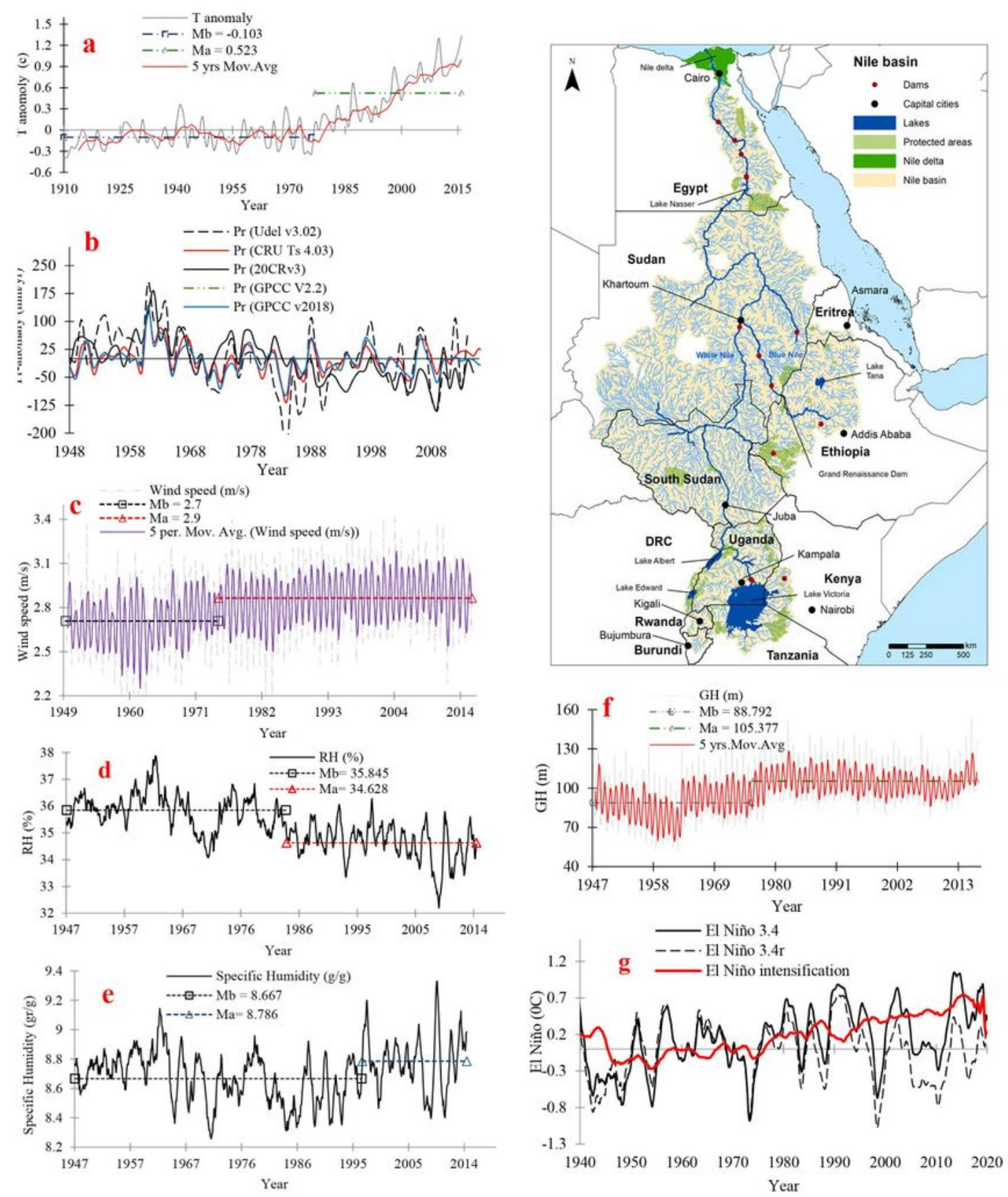

Figure 1

A detailed map of the Nile river basin. Map of the Nile river basin showing the main riparian of the Nile. The observed streamflows analysed are taken from the Blue Nile station in Khartoum, Dongola station, and the Aswan station. The analysed precipitation, temperature, wind speed, relative humidity, 
geopotential height, specific humidity, soil moisture content, groundwater storage, surface runoff, standard precipitation index, standardised Precipitation-Evapotranspiration Index (SPEI), and hydrological drought index are averaged over the Nile river basin, as well as for each riparian country of the Nile. Metrological drought was analyzed for the main basin, reference and actual evapotranspiration, and agricultural drought were analyzed for each riparian country. Fig. 1 shows: (a) temperature anomaly, where $\mathrm{Mb}$ is the long-term average before the change point, and $\mathrm{Ma}$ the long-term average after the change point. (b) precipitation anomaly from five different datasets, (c) wind speed, (d) relative humidity, (e) specific humidity, (f) geopotential height, and (g) ERSST relative (without global warming signal) and absolute El Niño3.4 index time series, Fig $(1 \mathrm{~g})$ also shows El Niño3.4 intensification by global warming (red-line). Precipitation anomalies in Fig 1(b) are based on the following datasets: University of Delaware (Udel. V3.02), University of East Anglia's Climate Research Unit (CRU.TS4.03), 20th Century Reanalysis V3 Dataset (20CRv3), Global Historical Climate Network (GPCC V2.2), GPCC Full Data Monthly Product Version 2018 extended with GPCC Monitoring Monthly Product version 6 (GPCC V2018), and the NCEP/NCAR Reanalysis dataset. Fig. 1(a) shows the significant increase in the long-term average temperature anomaly from $-0.1^{\circ} \mathrm{C}$ over $1910-1976$ to $0.523^{\circ} \mathrm{C}$ over $1976-2017$. Rising air temperature together with high wind speed resulted in higher evapotranspiration and lower soil moisture content (SMC), given SMC and groundwater storage (GWS) have been decreasing at $0.84 \mathrm{~mm} /$ decade and 1.44 $\mathrm{mm} /$ decade, respectively since 1979 . The decrease in RH, SMC, and GWS had been the most significant in Uganda, Sudan, and northwestern Ethiopia where the increase in temperature, GPH, AET and wind stresses had also been the highest. Fig. 1 also shows a decreasing trend in precipitation at 16.2 $\mathrm{mm} /$ decade since 1970s, increasing trend in wind speed and zonal wind stress at $0.02 \mathrm{~m} /$ decade and $1.51 \mathrm{~m} 2 / \mathrm{s} 2 /$ decade respectively since 1975 , increasing trend in geopotential height (GPH) at 3.1 $\mathrm{m} /$ decade since 1976 , warming trend at $0.19^{\circ} \mathrm{C} /$ decade, and decreasing trend in relative humidity $(\mathrm{RH})$ since 1977. 

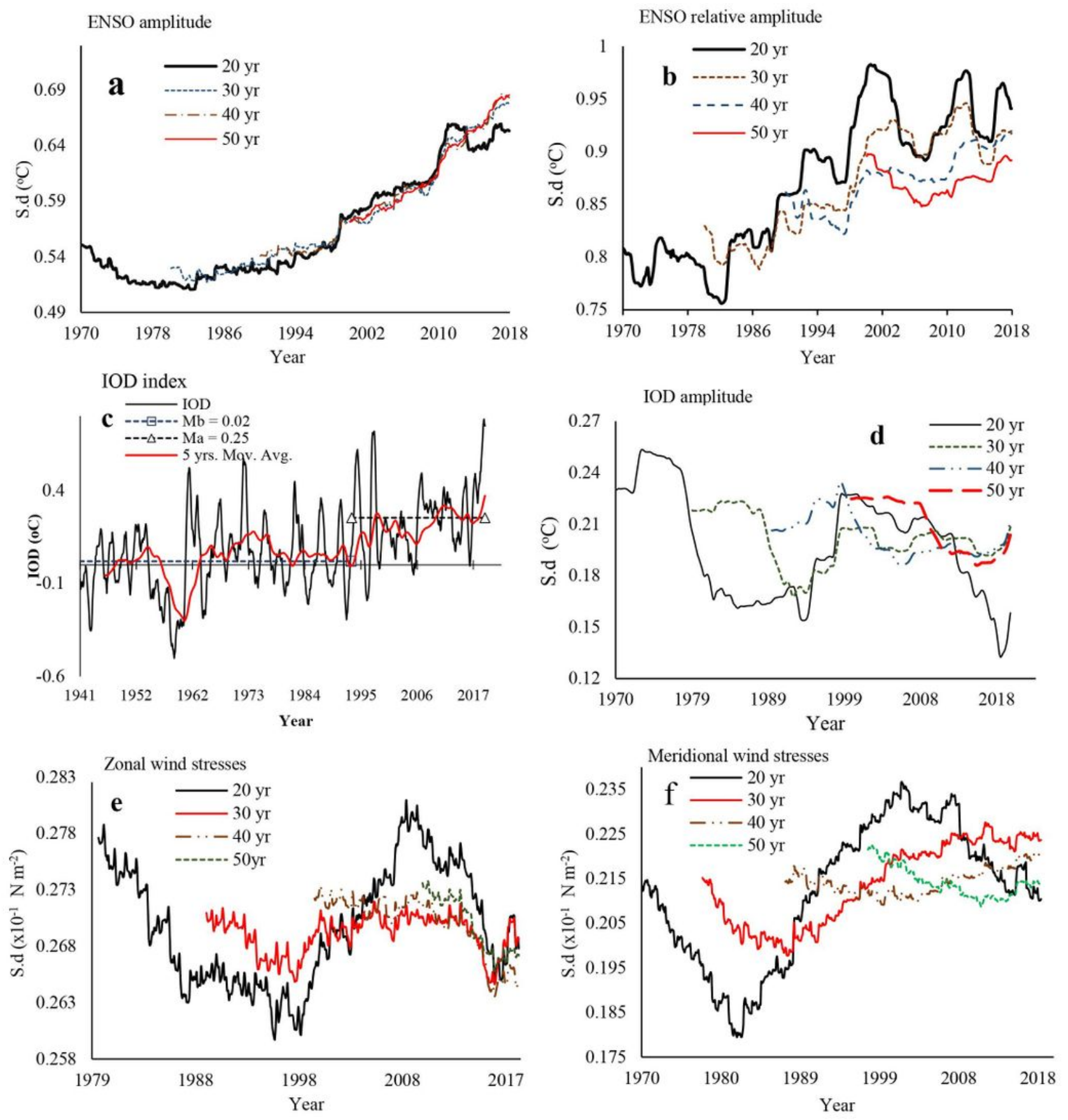

Figure 2

Observed ENSO and Indian Ocean dipole (IOD) amplitude, and zonal and meridional winds stresses over the NRB: ENSO and IOD amplitude (OC), defined as the standard deviation (s.d.) of the Niño3.4 and relative El Niño3.4 (El Niño3.4r) amplitude (a,b) and IOD index (d) over 20-, 30-, 40- and 50-year windows from 1950 to 2017, and IOD characteristics over the NRB (c) using the ERSST data sets. Zonal and meridional wind stresses amplitude (10-1 N m-2) are defined as the s.d. of zonal and meridional winds stresses over 20-, 30-, 40- and 50-year windows from 1950 to 2017, using NCEP/NCAR data sets from 1950-2017 (e, f). An increasing meridional wind amplitude (e) associated with a prominent anticyclonic 
circulation in southern NRB have contributed to the observed increasing intensity of recent El Niño events $(a, b)$. There is also a statistically significant in-phase, inter-annual relationship between meridional wind stress and El Niño over 1960-2017, and an in-phase, inter-annual relationship between zonal wind stress and El Niño over 1988-2017, while IOD, meridional and zonal wind stresses showed in-phase coherence after 2000s (supplementary Fig.8a-d). Warm spell duration (WSD), defined as the annual number of days contributing to events where 6 or more consecutive days experience a daily maximum temperature TX > 90th percentile, averaged over the NRB using the HadEX2 observational data set given in supplementary Fig. 1 a shows a linear increasing trend that is significant at 0.001 significant level ( $p$-value).
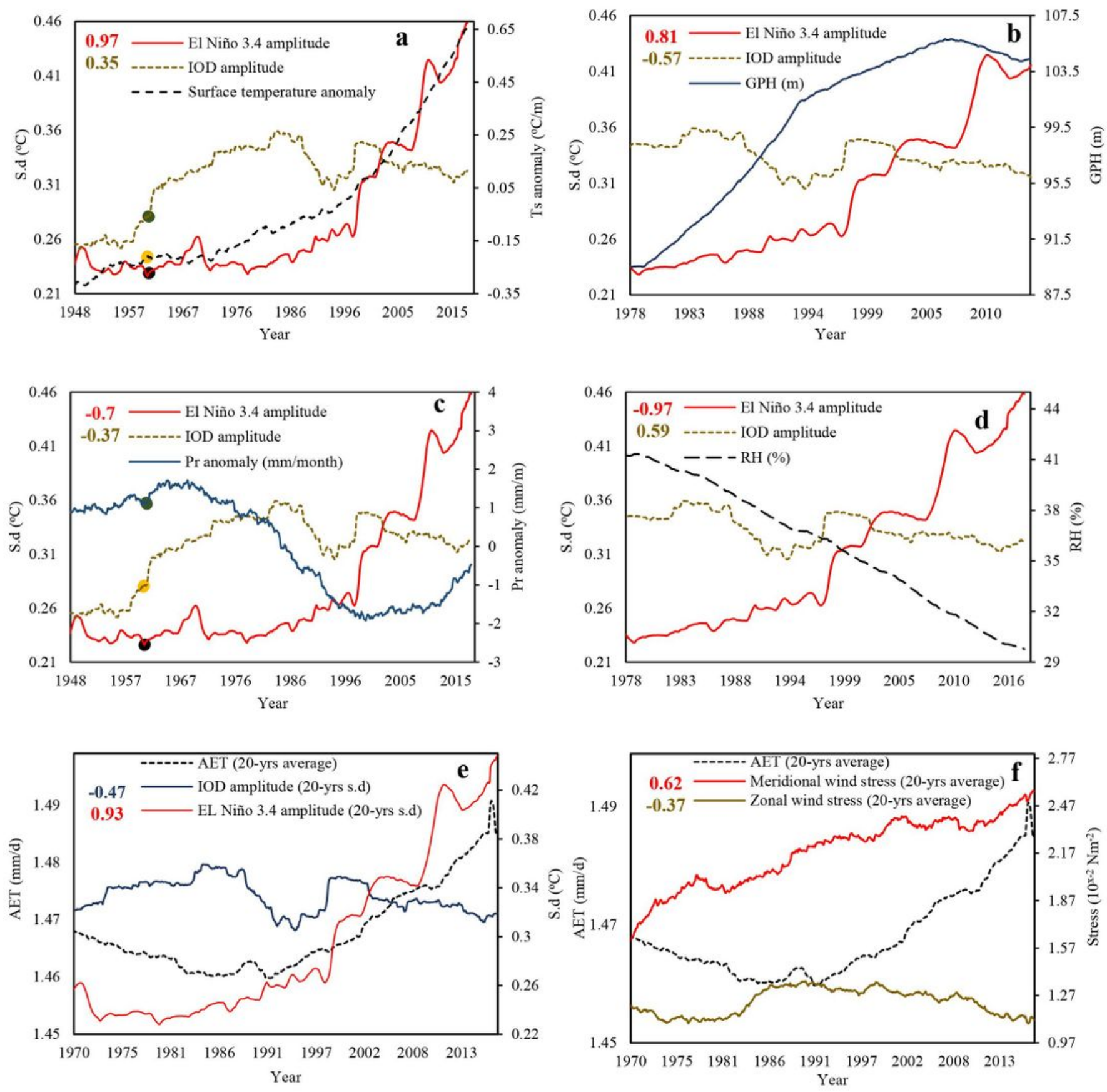

Figure 3 
ENSO and IOD Teleconnections on NRB hydroclimate. IOD and El Niño 3.4 amplitudes correlations with NRB surface temperature (a), GPH (b), precipitation anomaly (c), relative humidity (d), AET (e), and AET correlation with meridional and zonal wind stress (f). Surface temperature anomaly, GPH, precipitation anomaly, and relative humidity are computed over 30-year running periods from 1920 to 2017, El Niño 3.4 and IOD amplitude are the SD of EI Niño 3.4 and IOD indexes over 30-year windows from 1920 to 2017 using the ERSST data sets. The numbers in the top right are the cross-correlation coefficient between variables and IOD amplitude (brown colour) and El Niño 3.4 amplitude (red colour) at the $5 \%$ level. In a and c, black and yellow points represent neutral ENSO conditions and strong positive IOD in 1961, green point is the response on surface temperature "increase" and decrease in precipitation anomalies "decrease" in the same year 

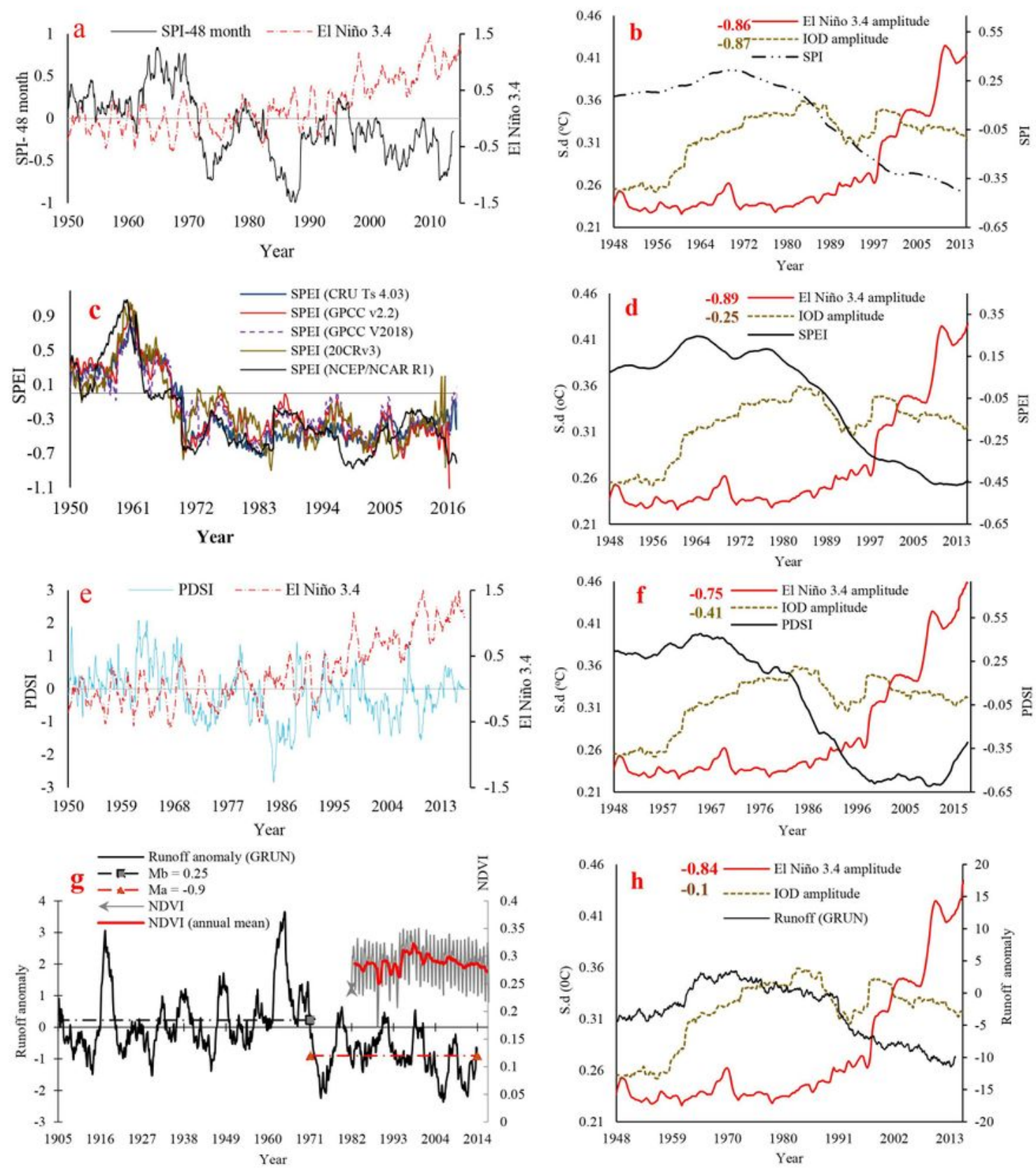

\section{Figure 4}

The influence of ENSO and IOD on drought conditions of NRB: (a) 48-month SPI vs EI Niño 3.4, (b) IOD and El Niño 3.4 amplitudes detrended cross correlations with SPI, (c) Standardised PrecipitationEvapotranspiration Index (SPEI) calculated using five precipitation data sets, all SPEI indices show a statistically significant drying trend $(p<0.05)$ since the 1970s. (d) IOD and El Niño 3.4 amplitudes detrended cross-correlations with SPEI, (e) self-calibrated PDSI (sc-PDSI) vs. El Niño 3.4, (f) IOD and EI 
Niño 3.4 amplitudes detrended cross correlations with sc-PDSI, (g) trend and variability of monthly runoff anomaly averaged over a 3-year moving window between 1902 to 2014 using GRUN- Runoff observationbased global gridded runoff. The right-hand side of Fig 4(g) shows the monthly Normalized Difference Vegetation Index (NDVI) computed from NOAA Climate Data Record (CDR) of AVHRR NDVI V5 and averaged over the entire Nile River basin. Figure 4(g) also shows the agricultural and vegetation cover response (drying) to the decline in runoff after 1970s. (h) IOD and El Niño 3.4 amplitudes detrended cross correlations with runoff anomaly. The sc-PDSI shows a statistically significant change point in 1988, where the long-term average PDSI decreased from 0.125 between 1960 and 1988 to -0.185 between 1988 and 2014 with a statistically significant declining trend of 0.58/decade and a strong correlation with El Niño events. After 1970s, the wavelet coherence (WTC) between EI Niño, IOD, sc-PDSI and SPI shows significant anti-phase relationships, which demonstrates that more frequent and severe EI Niño, IOD and SST gradient over the Arabian Sea (WTIO) in recent years, has led to more severe droughts in NRB. From WTC and strong negative correlations between SPI, SC-PDSI and WTIO, NRB's hydroclimate is shown to be more strongly influenced by WTIO than by IOD (see supplementary Figs. 11 and 12). In b, $d$, $f$, and $h$, the SPI, SPEI, Sc-PDSI, runoff indices were computed over 30-year running periods from 1920 to 2017, El Niño 3.4 and IOD amplitude are the SD of El Niño 3.4 and IOD indexes over 30-year windows from 1920 to 2017 using the ERSST data sets. The numbers in the top right of $b, d, f$, and $h$ are the detrended crosscorrelation coefficient between drought indices and IOD amplitude (brown colour) and El Niño 3.4 amplitude (red colour) at the $5 \%$ level. 

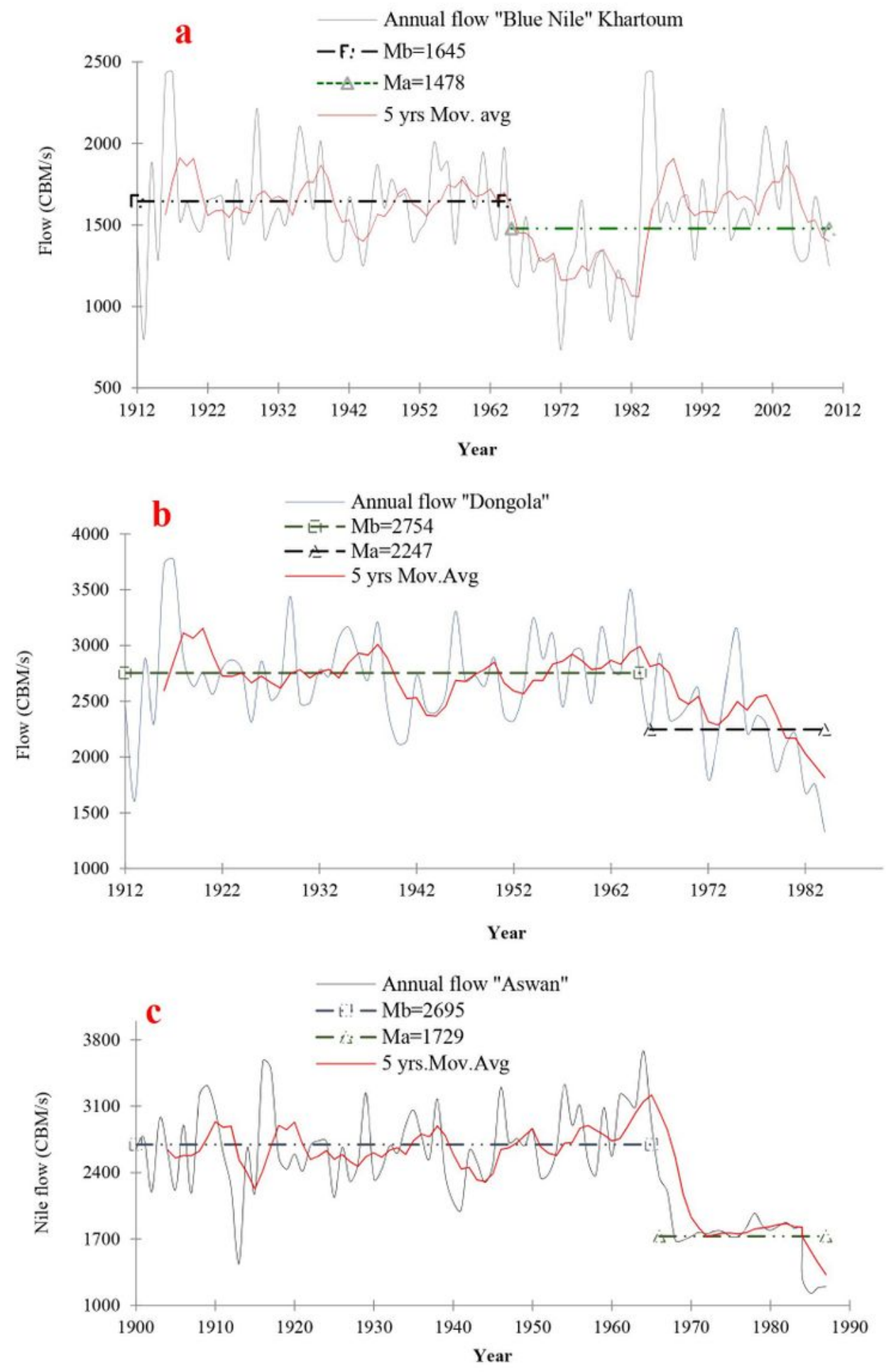

\section{Figure 5}

Observed annual flows: (a) Blue Nile flow, (b) Dongola station flow, and Aswan station flow (c). In Fig 5a, the annual flow of the Blue Nile river decreased from 1645 CBM/s over 1912-1964 to $1478 \mathrm{CBM} / \mathrm{s}$ over 1964-2012, with a decreasing trend of about 13.7 CBM/decade after 1964, due to higher AET losses, warmer WTIO and IOD, and more intensive El Niño events. 

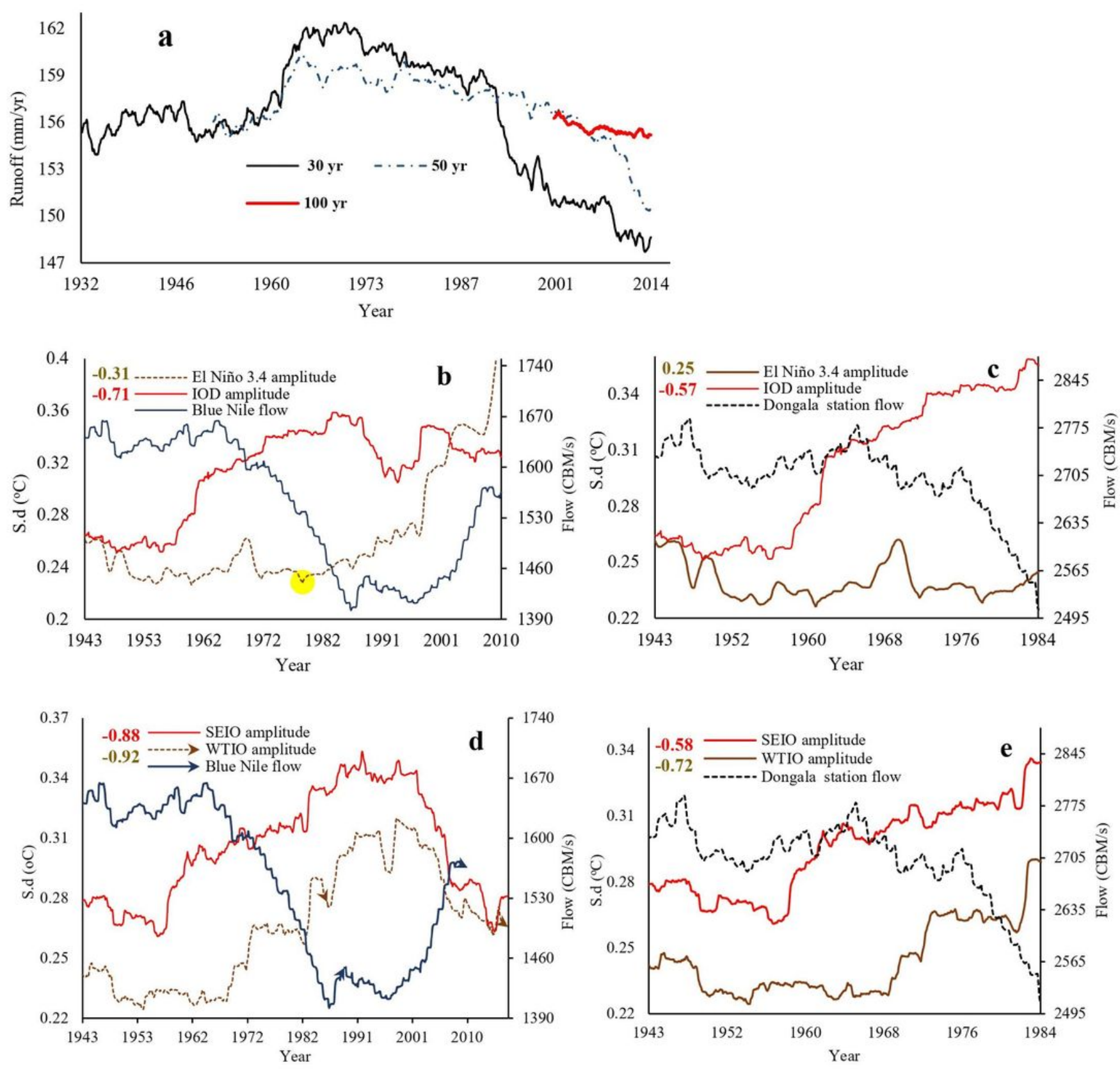

Figure 6

Teleconnections between NRB's flow variability, ENSO and IOD. (a) 30-, 50- and 100-year moving average of annual runoff over the Nile River basin (a). Responses of NRB flow variability to El Niño events, IOD amplitude and the IOD two pole amplitudes i.e. western pole amplitude (WTIO) over the Arabian Sea and eastern pole amplitude (SEIO) based on the detrended cross correlation between NRB flow at Blue Nile and Dongala stations and EI Niño 3.4, IOD amplitudes (b, c), SEIO, and WTIO amplitudes (d, e), respectively. The NRB flow are computed over 30-year running periods from 1913 to 2012 for the Blue Nile station, and from 1913 to 1984 for Dongala station. EI Niño 3.4, IOD, SEIO, WTIO amplitudes are computed as the s.d. of the EI Niño 3.4, IOD, SEIO, WTIO over 30-year windows from 1913 to 2017, using the ERSST data sets. The peak correlation between IOD and the Nile flow occurred one year earlier than 
that between El Niño and the Blue Nile flow, which agrees with the WTC between IOD and El Niño (i.e. one lead the other as shown in supplementary Fig. 6a, b). From the WTC and strong negative correlations between Nile flow, SEIO, WTIO and IOD, the Nile flow is more strongly teleconnected to IOD, SEIO and WTIO than to El Niño at inter-annual and inter-decadal time scales.

(a) El Nino stream function $\left(\mathrm{m}^{2} / \mathrm{s}\right)$



(e) El Nino U-wind (m/s)

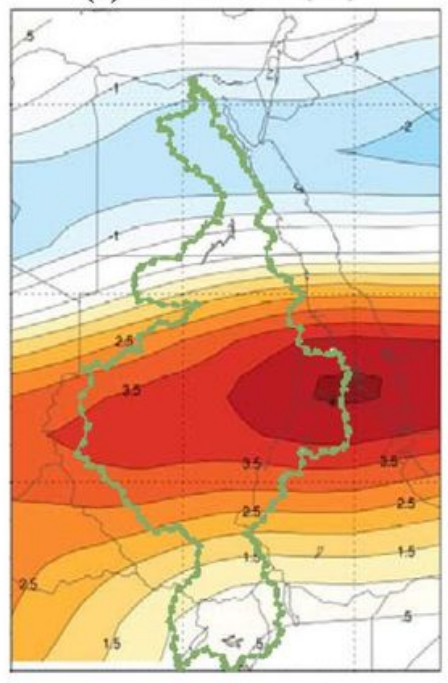

(b) La Nina stream function $\left(\mathrm{m}^{2} / \mathrm{s}\right)$

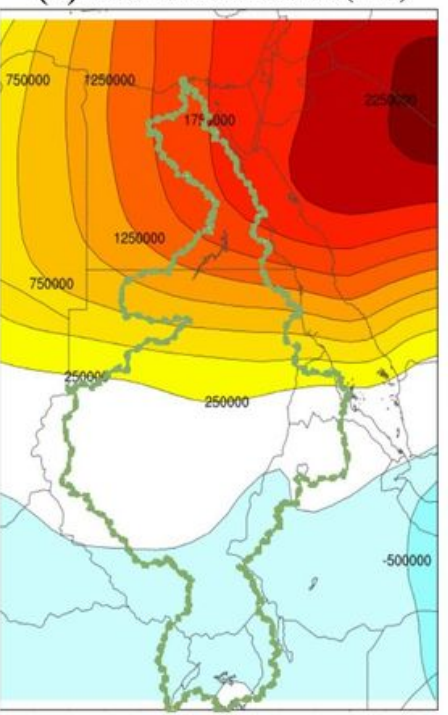

(f) La Nina U-wind ( $\mathrm{m} / \mathrm{s})$

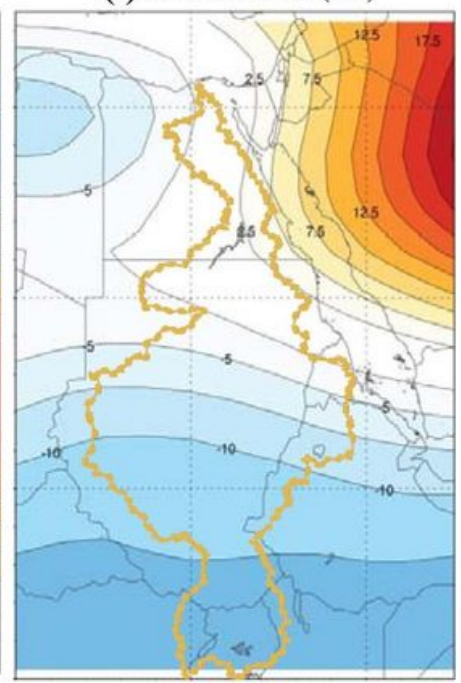

(c) El Nino geopotential height (m)

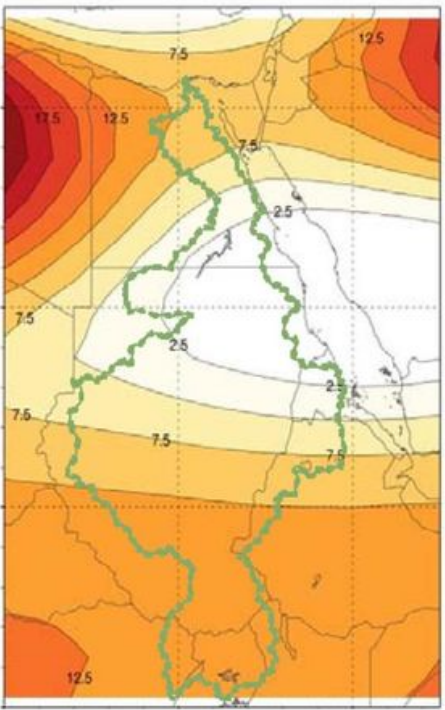

(g) El Nino meridional-wind

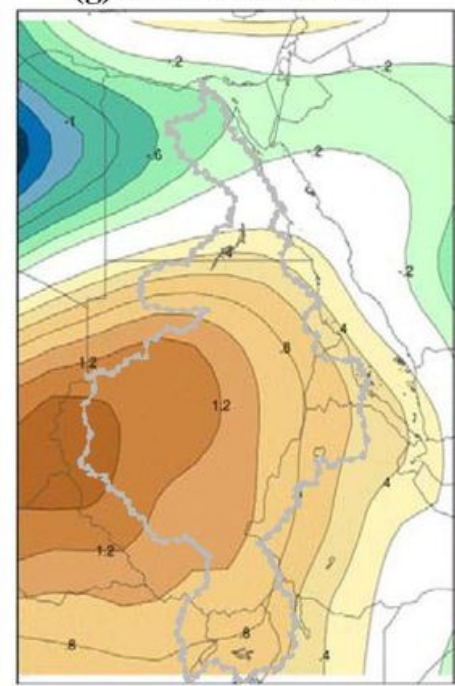

(d) La Nina geopotential height (m)



(h) La Nina meridional-wind

\section{Figure 7}

The effect of ENSO to the atmospheric circulation over NRB shown by the 750-mb stream function anomaly associated with El Nino (a) and La Nina (b) episodes (shaded contours, red/brown for positive and blue for negative anomalies), 300-mb geopotential height anomaly associated with El Nino (c) and La Nina (d) episodes, zonal and meridional wind anomaly patterns associated with El Nino (e, g) and La Nina (f, h) episodes, respectively. The signals between ENSO and GPH, stream functions, and meridional/zonal wind in the troposphere demonstrates the teleconnection between El Niño and the atmospheric circulation over of NRB. The warming over the Arabian sea and stronger El Niño, the 
southward shift of the lower atmospheric stream functions and meridional winds, and the westward shift of zonal winds have together contributed to worsening droughts observed in NRB in recent years
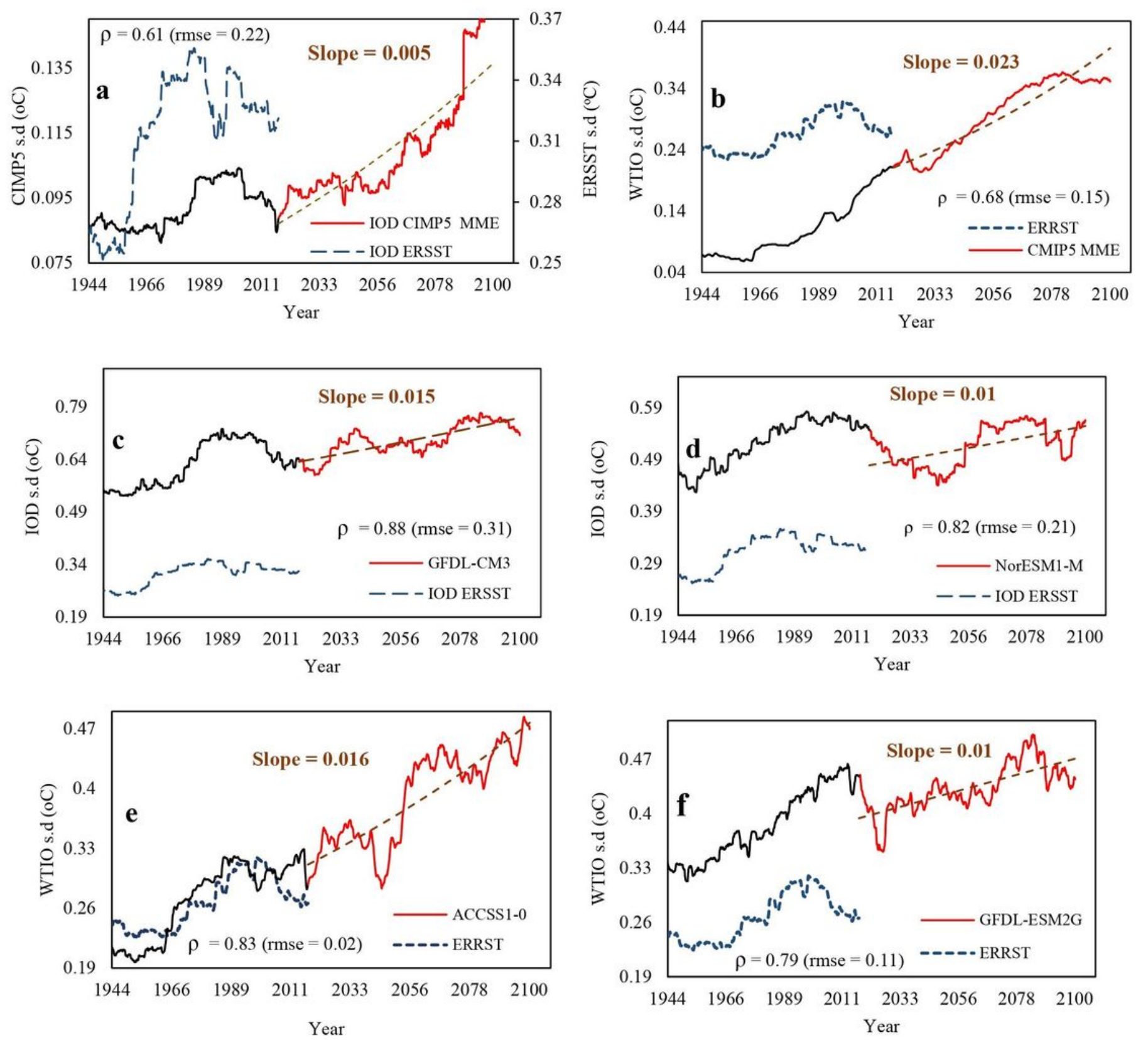

\section{Figure 8}

Time variation of simulated IOD and WTIO amplitude $(a, b)$, the multi-model ensemble (MME) of the IOD was computed as the difference between West $\left(50^{\circ} \mathrm{E}\right.$ to $70^{\circ} \mathrm{E}$ and $10^{\circ} \mathrm{S}$ to $\left.10^{\circ} \mathrm{N}\right)$ and Eastern $\left(90^{\circ} \mathrm{E}\right.$ to $110^{\circ} \mathrm{E}$ and $10^{\circ} \mathrm{S}$ to $0^{\circ} \mathrm{N}$ ) SST of the Indian ocean from 34 climate models. In a, the 30-year running IOD amplitudes from ERSST over the period 1913-2017 are also shown (blue lines). The WTIO from the MME (b) was calculated as area weighted average of the Indian Ocean SST over the Arabian sea $\left(50^{\circ} \mathrm{E}\right.$ to $70^{\circ} \mathrm{E}$ and $10^{\circ} \mathrm{S}$ to $10^{\circ} \mathrm{N}$ ) in each model simulations. The 30-year running WTIO amplitudes from ERSST over the period 1913-2017 are also shown (blue). Pearson correlation coefficients between the best models 
and observations (ERSST data), are displayed (c-f). The slope is the linear trend estimated at the $5 \%$ level based on the Mann-Kendall test.
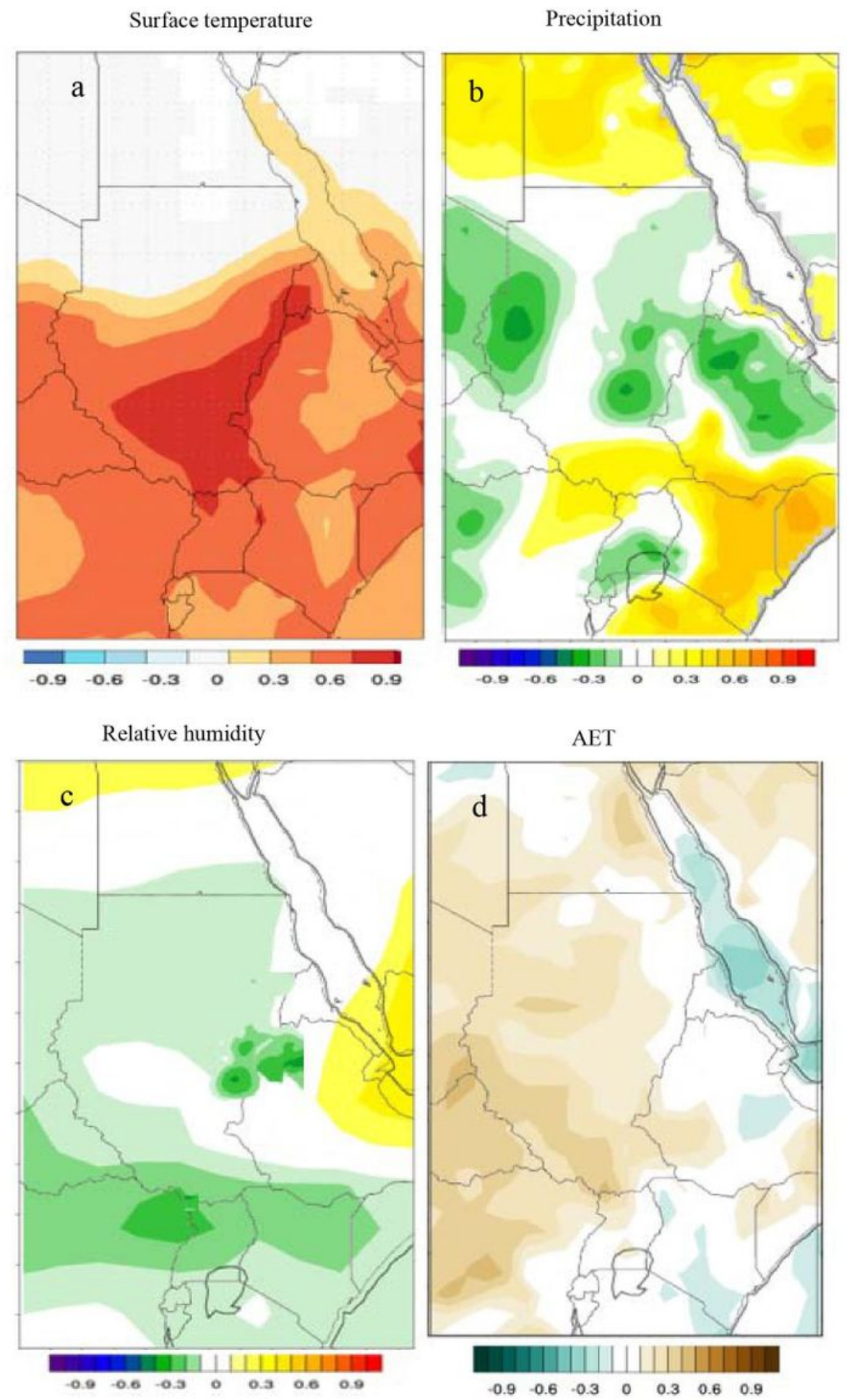

\section{Figure 9}

Spatial correlation of Niño 3.4 index with (a) surface temperature, (b) precipitation, (c) relative humidity, (d) AET between 1948:2017 ( $p<5 \%$ ). In $b$, the strong negative correlation between El Niño and precipitation in lowland of Ethiopia, Sudan, Uganda, Rwanda, and Burundi indicates that El Niño plays a 
dominant role in precipitation variability (reduction) in these countries. On the other hand, there is a strong positive correlation between El Niño and precipitation in Kenya, Tanzania, and Egypt implying an increase in precipitation in these countries. In d, the spatial relationship between AET and El Niño is a mirror-opposite of the relative humidity- El Niño relationship (c) because of the strong dependence between relative humidity and evaporation rate i.e. a decrease in relative humidity causes evaporation rate to increase.


Relative humidity
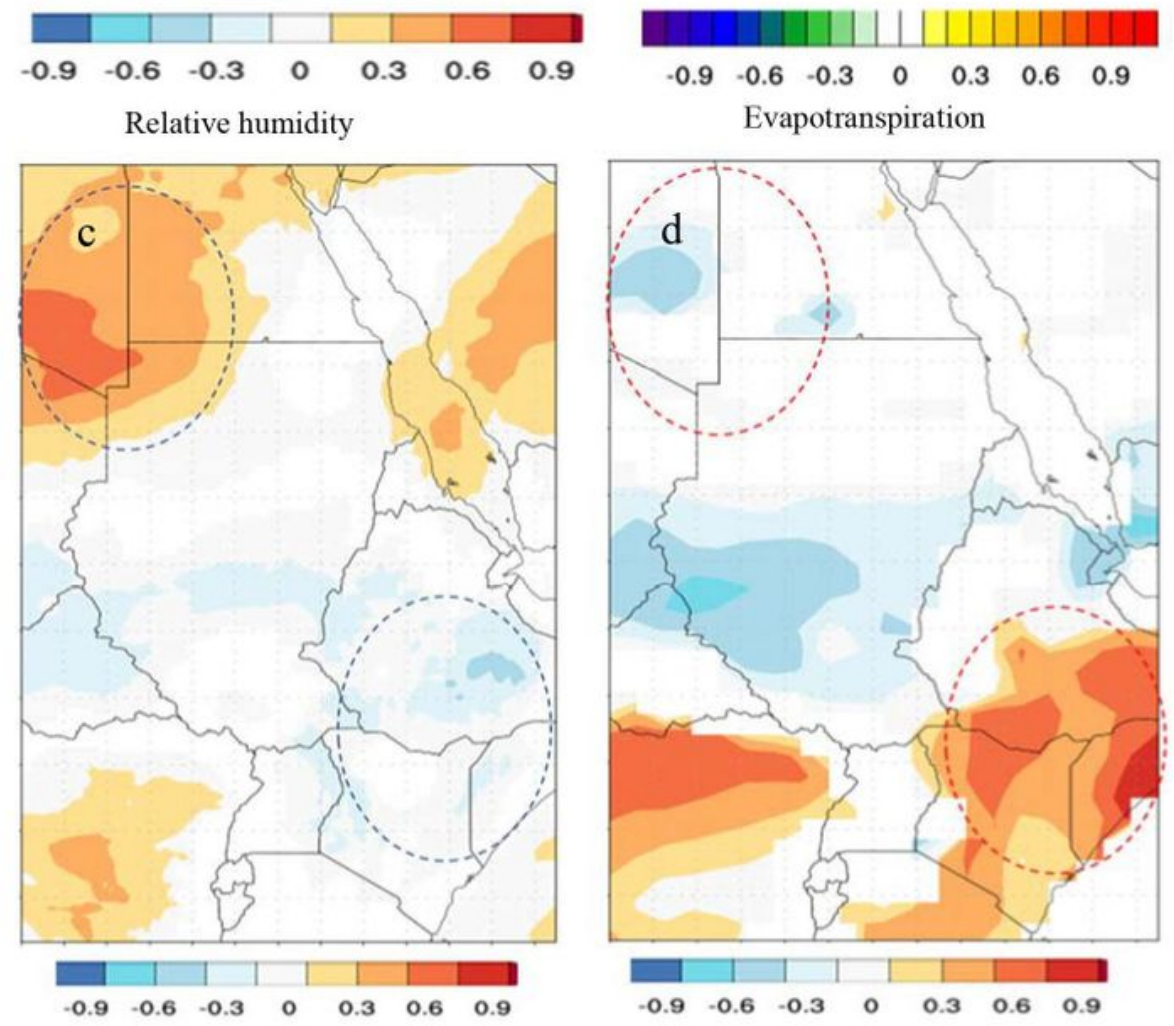

Figure 10 
Spatial correlation of IOD index with (a) surface temperature, (b) precipitation, (c) relative humidity, and (d) AET between 1948:2017 ( $<<5 \%$. In a, IOD intensified ENSO-induced warming in the upper part of the NRB. In b, IOD seems to amplify ENSO impact on the NRB's precipitation variability with reduced precipitation in Eritrea, Ethiopia, Sudan, Congo, and Egypt, and increased precipitation over Uganda, Kenya, Tanzania, Burundi, and Rwanda. In c and d, RH and AET show an almost opposite pattern to their relationship with ENSO.

\section{Supplementary Files}

This is a list of supplementary files associated with this preprint. Click to download.

- SupplementaryScientificRept.pdf 